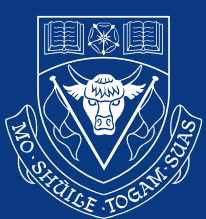

UNIVERSITY OF CALGARY
THE SCHOOL OP PUBtic Pohí

SPP Research Paper

Energy $\mathcal{\&}$ Environment $S_{\epsilon}$

\section{TRANSMISSION POLICY IN ALBERTA AND BILL 50}

\author{
Jeffrey Church
}

Department of Economics, University of Calgary

\section{William Rosehart and John MacCormack}

Department of Electrical Engineering, University of Calgary

\section{Revised Discussion Paper}

November 2, 2009

Original Version Presented at the School of Public Policy Workshop,

Electricity Transmission Policies: Issues and Alternatives

held October 7, 2009 at the Hotel Arts, Calgary, Alberta

We would like to express our appreciation to participants at the "Electricity Transmission Policies: Issues and Alternatives" workshop sponsored by the School of Public Policy for comments and suggestions and, in particular, Marcy Cochlan, Randy Stubbings, Joseph Doucet, Larry Ruff, Richard Tabors, Steven Stoft, Dan Levson, Bob Baer, Aidan Hollis, Carl Fuchshuber, Tom Cottrell, Cory Temple and Evan Bahry. The graciousness and spirit with which they provided comments does not of course imply endorsement of our approach or conclusions. In addition, we benefited from the comments of an anonymous referee.

The views expressed in these publications are those of the authors' alone and should not be interpreted as the views of the School of Public Policy or of its supporters, staff or boards. 


\section{EXECUTIVE SUMMARY}

\section{Background}

Various plans developed by the Alberta Electric System Operator (AESO) have indicated for some time a need for expansion of the Alberta electrical transmission system. This was also recommended in Alberta's Provincial Energy Strategy released in December of 2008 and it seems generally accepted that some expansion is appropriate. However, there are many complex issues involved in determining the exact nature and extent of this expansion. These issues have traditionally been sorted out through the work of the AESO, followed by a formal application and open hearings by the regulator, the Alberta Utilities Commission (AUC).

In June of 2009 the Alberta government proposed new amendments (Bill 50) to the Electric Utilities Act, the Hydro and Electric Energy Act, and the Alberta Utilities Commission Act that significantly alter the regulatory process for the approval of new high-voltage transmission lines. Bill 50 introduces the concept of Critical Transmission Infrastructure (CTI), defined as transmission and related facilities determined by the government to be in the public interest. Under this Bill, CTI is subject to substantially reduced regulatory oversight by the Alberta Utilities Commission (AUC). It suspends the regulatory framework established under the Electric Utilities Act requiring the Alberta Electric System Operator (AESO) to demonstrate a "need" for the facilities and a finding by the AUC that the facilities are in the public interest.

Bill 50 also identifies the following four transmission projects as critical infrastructure:

- Two High Voltage Direct Current (HVDC) transmission facilities in the Edmonton-Calgary corridor, each with a minimum capacity of 2,000 megawatts (MW).

- A double circuit $500 \mathrm{kV}$ alternating current line between Edmonton and the GibbonsRedwater region.

- A new $240 \mathrm{kV}$ substation in southeast Calgary.

- Two single-circuit $500 \mathrm{kV}$ alternating current lines between Edmonton and Fort McMurray.

The estimated cost for these four projects is approximately $\$ 5.7$ billion. The cost for the two HVDC lines in the Edmonton-Calgary corridor is more than $\$ 3.1$ billion. The four projects in Bill 50 are a subset of the $\$ 14.5$ billion for transmission projects identified in the Long-term Transmission System Plan filed by the AESO in June of 2009.

\section{Objectives}

The objectives in this study are to provide:

- a review of the institutional framework instituted by the government's transmission policy.

- a test of the efficiency implications of the government's transmission policy based on a comparison of the costs and benefits of the two large-capacity HVDC lines proposed for the Edmonton-Calgary corridor relative to alternatives.

- a brief evaluation of the proposed regulatory process under Bill 50. 


\section{Summary of Conclusions}

- The absence of strong locational price signals within the current transmission pricing approach creates the potential for excessive demand for expansion of transmission facilities and potential for discrimination against generation located near load or demand. This, in turn, can result in distortions in the market for electricity and in higher costs of delivered electricity to consumers.

- In the absence of strong locational price signals, the regulatory process is critical in terms of providing a check against excessive or inefficient overbuilding of transmission facilities. Inefficiency arises when the costs exceed the benefits of incremental facilities.

Based on an efficiency assessment of the two, large-capacity HVDC lines proposed for the Edmonton-Calgary corridor, there is concern that, under Bill 50, there is inadequate attention to the costs of inefficient overbuilding and the consequence of higher than necessary electricity costs for Alberta consumers. Of particular concern is the fact that under Bill 50 there are no opportunities for a transparent, independent and arm's-length review of the benefits and costs of projects deemed critical infrastructure.

- The analysis presented compares the costs of resolving the anticipated north-south transmission congestion with the two high-voltage direct current power lines versus the costs of a generation-only solution. It is not argued that a generation-only solution is optimal. Rather, a mix of generation and transmission expansion will likely be most efficient.

- Various cases are considered to take into account such things as different rates of growth of wind power and treatment of greenhouse gas emissions. Under all cases any increased costs of generation were found to be significantly lower than the cost of building the two HVDC lines. The additional cost associated with the two HVDC lines ranged from $\$ 1.1$ billion to $\$ 2.2$ billion above that for the generation-only case, while maintaining supply adequacy and continuing to meet reliability requirements. The lowest additional cost estimate assumes no additional wind generation and that greenhouse gas offset costs are zero. The largest estimates assume that the two HVDC lines do not reduce line losses. Our estimates for the additional cost associated with the two HVDC lines under the most probable conditions range from $\$ 1.7$ billion to $\$ 1.9$ billion.

- There are advantages and disadvantages to using an independent regulator to assess whether a transmission project is in the public interest. The former, at least in theory, include the greater likelihood that the long-term perspective will dominate short-term political interests and a regulator likely has a greater ability to draw on expertise, process, and public participation to evaluate and adjudicate complex issues. The process also requires the regulator, through written decisions, to provide and document the rationale for each decision. The disadvantages include the fact that regulatory hearings are often costly and decisions may not be timely. In this context it may well be that Bill 50 is a response to certain frustrations and costs associated with obtaining regulatory approval for some projects. However, unilateral government action in such cases may only provide a superior solution if there is widespread agreement on the problem, time is of the essence and the cost of not addressing the problem is far more expensive than exploring alternatives. Our results, showing that the two large HVDC lines that are proposed are economically inefficient and unwarranted given the AESO's assumptions and forecasts, point to the 
benefit of a regulatory process, and raise doubts that the state of reliability and supply adequacy indicate the need for an emergency response. If the existing regulatory process is found to be dysfunctional (and there appears to be frustration on the part of generators at the pace of transmission expansion), the answer may be that it is better to institute regulatory reform than abandon regulation. The uproar over Bill 50 and the two HVDC lines may also highlight the value of a regulatory process. Having the debate over highly complex transmission investment issues carried on in the media through duelling public relations campaigns and websites is not likely to serve the public interest.

\section{Qualifications}

Given the importance of electricity to the welfare of Albertans, and the heightened political sensitivities to transmission policy, it is important to emphasize what this paper does not do and what we do not conclude.

- This study is not a critique of the existing market design and institutions in Alberta, but rather is focused on concerns with transmission policy and Bill 50. We illustrate that those concerns might well be material by considering the economics of the two HVDC lines in the Edmonton-Calgary corridor. We have not undertaken an analysis of the three other CTI projects in Bill 50.

- This study does not conclude that the Alberta experience with regulatory restructuring and the introduction of competition and market forces into the Alberta Interconnected Electric System (AIES) is a failure.

- This study does not propose specific pricing policies for transmission in Alberta. Nor does it provide suggestions for the planning process and the approval of investment in transmission in Alberta. These are important issues. Given the time and resources available they could not be properly addressed in this paper.

- We do not conclude that any north-south reinforcement of the transmission grid is inefficient or not required. We do not conclude that a generation-only solution is optimal. A mix of generation and transmission expansion may be optimal.

- Our conclusion is that the large cost and capacity of the two HVDC lines, 4,000 megawatts, is an overbuild that is not warranted by its economics. There may be other benefits that we have not considered that justify the two HVDC lines. However, for these considerations to overturn our conclusion that the two HVDC lines are inefficient, it is necessary to establish that the benefits not counted in our analysis are worth more than $\$ 1.7$ billion to $\$ 1.9$ billion, and that those benefits cannot be achieved by a less expensive alternative. Prebuilding transmission in advance to increase investment in generation, strengthening the system to increase intertie capacity, the mitigation of market power, and minimization of land impact and rights of way are examples of the benefits that have been suggested.

- An additional benefit of the two HVDC lines that has been suggested is that they are necessary to meet reliability requirements. However, reliability requirements can be met in a variety of ways. The generation-only alternative considered in this study is one alternative that continues to meet reliability requirements. 
- A particular concern is that the development of congestion and/or a more efficient congestion policy in the AIES would require a costly redesign of the market. While this may or may not be true, it is not sufficient to merely assert that any redesign instituted because of congestion or implementation of a different congestion policy would be more costly than substantially overbuilding transmission facilities. Instead it is necessary to show that the costs from redesign would exceed the extra costs associated with the congestionfree policy. Our results show that the costs of a congestion-free policy, in terms of the costs of delivered electricity, can be substantial. 


\subsection{INTRODUCTION AND OVERVIEW}

In June of 2009 the Alberta government proposed new amendments to the Electric Utilities Act, the Hydro and Electric Energy Act, and the Alberta Utilities Commission Act. The amendments, known as Bill 50, ${ }^{l}$ significantly alter the regulatory process for the approval of new high-voltage transmission lines in Alberta. Bill 50 introduces the concept of Critical Transmission Infrastructure (CTI), transmission facilities determined by the government to be in the public interest. Under Bill 50, CTI is subject to substantially reduced regulatory oversight by the Alberta Utilities Commission (AUC). The AUC's jurisdiction will be limited to issues arising from the siting of the facilities. For power lines deemed critical, Bill 50 suspends the regulatory framework established under the Electric Utilities Act requiring the Alberta Electric System Operator (AESO), the organization that plans the province's transmission grid, to demonstrate a "need" for the facilities Bill 50 also suspends the requirement for the regulator to find that the facilities are in the public interest. ${ }^{2}$

In addition to changing the regulatory process for CTI, Bill 50 also identifies four transmission projects as critical infrastructure. These are: ${ }^{3}$

(i) Two High Voltage Direct Current (HVDC) transmission facilities in the EdmontonCalgary corridor, each with a minimum capacity of 2,000 megawatts.

(ii) A double circuit $500 \mathrm{kV}$ alternating current line between Edmonton and the GibbonsRedwater region.

(iii) A new $240 \mathrm{kV}$ substation in southeast Calgary.

(iv) Two single-circuit $500 \mathrm{kV}$ alternating current lines between Edmonton and Fort McMurray.

The estimated cost for these four projects is approximately $\$ 5.7$ billion. ${ }^{4}$ The cost for the two HVDC lines in the Edmonton-Calgary corridor is more than $\$ 3.1$ billion. ${ }^{5}$ The four projects in Bill 50 are a subset of the $\$ 14.5$ billion for transmission projects identified in the Long-term Transmission System Plan filed by the AESO in June of $2009 .^{6}$

1 http://www.assembly.ab.ca/ISYS/LADDAR_files/docs/bills/bill/legislature_27/session_2/20090210_bill-050.pdf.

2 The AESO was established by Section 7 of the Electric Utilities Act. Under the Electric Utilities Act the AESO is responsible for the operation of the Alberta Interconnected Electric System, including the terms of access for generators to connect to the transmission grid and arranging for the expansion and enhancement of the transmission grid (Section 15). The transmission grid is privately owned.

3 Bill 50 2(13).

4 AESO Long-term Transmission System Plan at p. 56, June 2009. See also talk about Bill 50, Alberta Department of Energy, September 2009. The government includes the recently approved southern system reinforcement project as CTI. However, it is not one of the projects identified as CTI in Bill 50 and was approved under the existing regulatory requirements. See Alberta Utilities Commission, Alberta Electric System Operator, Needs Identification Document Application, Southern Alberta Transmission System Reinforcement, Decision 2009-126, September 8, 2009. Adding the cost of the southern reinforcement project ( $\$ 2.5$ billion) to the $\$ 5.7$ billion of the four CTI projects gives approximately $\$ 8.1$ billion which is the figure sometimes quoted as the cost of the Bill 50 projects.

5 Powering Albertans, AESO p. 12.

6 AESO Long-term Transmission System Plan, June 2009,

http://www.aeso.ca/downloads/AESO_LTTSP_Final_July_2009.pdf, Accessed Sept 23, 2009. 
Bill 50 is consistent with Alberta's Provincial Energy Strategy emphasis on the urgent need to strengthen Alberta's transmission grid. ${ }^{7}$ The motivation for Bill 50 and the four projects deemed CTI follow from a perception that "The need for major new transmission is critical." 8 There has been limited expansion of any significance to the transmission grid in Alberta since the 1980s which, coupled with significant increases in load and generation growth, ${ }^{9}$ has raised concerns about congestion and system reliability. ${ }^{10}$ The concern is that the reliability of the transmission grid will be impaired as it operates near its limits, and that the grid will not be able to support the requirements of large load centres, especially Calgary, thereby undermining supply adequacy. There is also a desire to improve transmission efficiency and reduce line losses. ${ }^{11}$ Line losses were $\$ 236$ million in 2008 and are forecast to be $\$ 126$ million in 2009. ${ }^{12}$

The government's motivation is not, however, limited to a concern about keeping the lights on. The government's transmission policy makes explicit its view that an unconstrained transmission grid - a transmission network that does not limit the supply from any generatoris a key element of its goal to establish and promote a competitive generation sector. ${ }^{13}$ A cornerstone of the government's transmission policy is "that transmission is a public good that must be available in advance of need" 14 and failure to provide adequate transmission capacity will reduce development of new supply. Unconstrained and available transmission capacity ensures that generators are not deterred from making investments in capacity by concerns that they will be constrained from selling power due to limits on their access to the transmission grid. An unconstrained transmission grid also means that the province is one integrated market for electricity, with a common price established by bidding in the power pool. The existence of constraints on the transmission grid could create regional markets.

This paper has three objectives. They are to provide:

(i) a review and analysis of the institutional framework instituted by the government's transmission policy. That policy, first articulated in the Alberta Department of Energy's

7 See Department of Energy, Launching Alberta's Energy Future: Provincial Energy Strategy, at http://www.energy.gov.ab.ca/Initiatives/strategy.asp.

8 talk about Alberta's Electricity Transmission System, Department of Energy, July 2009.

9 Load refers to "an end-use device or a customer that receives power from the electric system. Often load is used as synonymous with demand". S. Stoft, Power System Economics, Piscataway, New Jersey: IEEE Press, at p. 448.

10 There has been some expansion and addition of new lines. For instance, ATCO Electric's Dover to Whitefish line went into service in 2004 . This line is $350 \mathrm{~km}$ long and cost just under $\$ 100$ million. See ATCO Electric Press Release, ATCO Electric First Canadian Company to Take Home International Edison Award, June 21, 2005.

Line losses are energy losses due to heat from resistance to electrical current flow on the transmission lines.

12 AESO Transmission - Loss Factors - Calibration Factors -2009 http://www.aeso.ca/downloads/2009_Rider-EReport_Layout_Q4_2009_SEP_24_2009.pdf, Accessed October 22, 2009.

13 http://www.energy.gov.ab.ca/Electricity/pdfs/transmissionPolicy.pdf.

14 talk about Alberta's Electricity Transmission System, DOE, July 2009. The government's definition of a public good differs from that generally accepted in economics. In economics a public good is defined by two characteristics: non-rivalry in consumption and non-excludability. Non-rivalry in consumption means that consumption by one does not reduce the benefits from consumption by another. Non-excludability means that it is difficult or very expensive to stop someone from consuming the good. Transmission is both excludable and subject to congestion meaning it is not a public good as conventionally defined. 
policy paper, Transmission Development: the Right Path for Alberta, ${ }^{15}$ and formalized in the Transmission Regulation ${ }^{16}$ governs transmission pricing, planning and investment in the Alberta Interconnected Electric System (AIES).

(ii) a quantitative assessment of the efficiency of Alberta's transmission policy by comparing the costs and benefits of the two large-capacity HVDC lines proposed for the EdmontonCalgary corridor, deemed critical under Bill 50, to an alternative generation-only solution.

(iii) an evaluation of the proposed regulatory process under Bill 50. The interesting question Bill 50 raises with respect to process is the nature of the costs and benefits of the existing regulatory approval process and whether they warrant, in the case of transmission, suspension of a public regulatory process.

\subsection{Summary of Conclusions}

Our conclusions related to these objectives are summarized below.

(i) Our review and analysis focused on the effective price of transmission for generators and its effect on generation location and demand for transmission. This analysis suggests the potential for excessive demand for expansion of transmission facilities and the potential for a system that discriminates against generation located near to load or demand, raising the cost to consumers of delivered electricity. The present pricing of transmission creates incentives that are likely to encourage an inefficient mix of transmission and generation assets and, to the extent that happens, raise the total costs of the AIES. In our view, Bill 50 is consistent with existing transmission policy and arises from the perception that the existing regulatory process is dysfunctional and incapable of implementing that policy. Given the transmission policy adopted by the government, it is important to have regulatory oversight to constrain the degree of inefficient overbuilding of the transmission grid. This inefficient overbuilding arises when the costs of incremental transmission facilities exceed their benefits. Our economic analysis of the two HVDC lines proposed under Bill 50 for the Edmonton-Calgary corridor shows that the extent of this inefficiency can be substantial.

(ii) We find the proposal to build the two HVDC lines in the Edmonton-Calgary path is an inefficient response to concerns over adequate supply and reliability. We illustrate this by comparing the cost of resolving the anticipated north-south transmission congestion with the two high-voltage power lines versus the costs of a generation-only solution. We do not argue that a generation-only solution is optimal. Indeed a mix of generation and transmission expansion may be optimal. Presumably the extent to which the two HVDC lines impose higher costs is even greater relative to the optimal mix of generation and transmission expansion.

\footnotetext{
15 http://www.energy.gov.ab.ca/Electricity/pdfs/transmissionPolicy.pdf.

16 http://www.qp.alberta.ca/570.cfm?search_by=alpha\&letter=T.
} 
Under all scenarios considered, the increased costs of generation in the generation-only solution, from re-dispatch and higher cost incremental expansion in the south (in some cases) to avoid violating the transfer limits on the existing north-south transmission path, were found to be significantly lower than the cost of building the two HVDC lines. The additional cost associated with the two HVDC lines ranged from $\$ 1.1$ billion to $\$ 2.2$ billion above that for the generation-only case while maintaining supply adequacy and continuing to meet reliability requirements. This increase in cost is the additional real resource cost associated with the provision of electricity to Albertans. The lowest additional cost estimate assumes no additional wind generation and that greenhouse gas offset costs are zero. The largest estimates assume that the two HVDC lines do not reduce line losses. Our preferred estimates for the additional cost associated with the two HVDC lines range from $\$ 1.7$ billion to $\$ 1.9$ billion.

Our study evaluates the cost of re-dispatching existing generation and/or locating new combined cycle gas-fired generators in southern Alberta as an alternative to the proposed HVDC transmission reinforcements between Edmonton and southern Alberta. We compare the relative costs of the two alternatives to determine which is the least costly: generation with lower-cost generation in the north plus transmission expansion (two HVDC lines), versus generation with higher incremental cost in the south. We do this by assuming that if the two HVDC lines are built, dispatch will be unconstrained. If the two HVDC lines are not built, then dispatch of generation in the north might be constrained by limits on the north-south transmission line. This will increase costs if lower-cost generation in the north is displaced by higher-cost generation in the south and if limiting flows on the north-south transmission path to current limits requires expansion of highercost capacity in the south instead of lower-cost capacity in the north. We compare the difference in the cost of generation between the HVDC and no HVDC case to determine the advantage of adding the two HVDC lines. If this advantage is less than the cost of installing the two HVDC lines, then the generation-only solution is least costly. Over the period 2008 to 2028, the net present value (NPV) of the annual costs of the planned HVDC transmission reinforcements are estimated to be $\$ 2.25$ billion. $^{17}$

We expect that the re-dispatch of generators because of a transmission constraint will raise the fuel costs of generation as it involves substituting southern generation with higher fuel cost for northern generation with lower fuel cost. However, if generation expansion in the south is required, the effect of the transmission constraint will also depend on the relative magnitude of the long-run unit costs of any additional generation. We have assumed that incremental generation added in the north is supercritical pulverized coal generation and incremental generation added in the south is combined cycle gas generation. In this case, the effect of a north-south transmission constraint is to substitute incremental combined cycle gas generation in the south for incremental supercritical pulverized coal generation in the north. If the long-run unit cost of supercritical pulverized coal generation is less than the long-run unit cost of combined cycle gas generation, then the transmission constraint, to the extent that it changes the pattern of incremental expansion, results in an increase in generation costs.

17 All net present value numbers reported in this study, unless otherwise indicated, are discounted back to 2008 and are in real 2008 dollars. 
We find that the benefits of the two high-voltage power lines in avoiding costs of generation re-dispatch and/or adding combined cycle gas generation in the south are limited by the development of significant wind capacity in southern Alberta. If wind capacity is installed as projected by the AESO in its long-term plan, then the incremental generation required to meet load in Alberta can be only coal-fired generation located in the Edmonton area even if the two HVDC lines are not built. ${ }^{18}$ The ENMAX Crossfield plant is expected to be operational in 2010, providing 120 MW to southern Alberta. Beyond this, no additional generation capacity in the south is required to re-dispatch generation such that north-south transfers remain within current limits. If the maintained assumption is that wind generation will be available as projected by the AESO, the only additional cost associated with not proceeding with the two high-voltage lines is the incremental variable cost differential caused by re-dispatch. There is no change to the pattern of incremental generation expansion if the two HDVC lines are not built if wind capacity develops as expected.

If we assume that wind power develops as forecast, then the net present value (NPV) of the cost of re-dispatching generators to maintain north-south transfers within estimated 2008 limits is expected to be $\$ 228$ million. This assumes generation dispatch will follow current patterns (observed generation dispatch). If all existing and forecast generation capacity is assumed to dispatch at its variable cost (variable cost dispatch), the NPV of the costs could be as low as $\$ 21$ million.

We also explore the sensitivity of our results to the costs of greenhouse gas emissions, the price of natural gas, line losses, and development of wind power.

If we assume the costs of greenhouse gas emissions are zero, then the variable cost advantage of coal generation over combined cycle gas generation becomes larger and the NPVs of the cost of re-dispatch rise to $\$ 245$ million (observed generation dispatch) or \$23 million (variable cost dispatch). We find that, for the costs of re-dispatch to equal the costs of the two HVDC lines, the price of gas (in real \$2008) would have to rise to $\$ 66.80 /$ GJ (observed generation dispatch) or $\$ 790.70 /$ GJ (variable cost dispatch). Both of these are dramatic increases over the price used by the AESO in determining long-run expected costs: approximately $\$ 7.50 / \mathrm{GJ}$.

The average line losses per year over 2008 and 2009 for the power grid are approximately $\$ 180$ million. The proposed north-south reinforcement can reduce but not eliminate these losses. If north-south reinforcement eliminated 25 per cent of these losses, then an additional cost of not introducing the two HVDC lines (and no other reinforcement alternative) from continued lines losses would have a NPV of \$292 million (\$2008). If the two HVDC lines eliminated 25 per cent of system line losses, then the NPV of the cost of the generation-only case is between $\$ 1.73$ billion and $\$ 1.94$ billion less than the cost of the two high-voltage lines.

18 This forecast does not include the impact of the Montana Alberta Tieline which will enable wind-energy producers in Montana to sell their output into Alberta. The expected in service date of this line is early 2011. This is an incremental source of energy into southern Alberta that would act to alleviate north to south loading on the Edmonton to Calgary transmission path. 
Given the AESO's assumptions regarding long-run unit costs inclusive of greenhouse gas costs, the long-run average cost of supercritical pulverized coal generation is greater than the long-run average cost (inclusive of greenhouse gas emission costs) of combined cycle gas generation at any capacity factor. The variable cost advantage of coal is no longer large enough to make up for its fixed cost disadvantage (from high capital costs) even at high capacity factors. If coal-fired generation is more expensive than combined cycle gas-fired generation, then the assumed trade-off with respect to incremental generationhigh cost in the south versus low cost in the north-does not exist.

Based on the AESO's forecasts of costs, coal capacity in the north is unlikely to be installed even if the two HVDC lines are built. If the coal generation is not built because it is not economic (as suggested by the AESO's assumptions), then there is likely little or no advantage and only a cost to building the two HVDC lines. Instead, incremental combined cycle gas generation should be located closer to load in the south.

We also explore the sensitivity of our results to the assumption that wind capacity in southern Alberta will develop as expected by the AESO. The assumption in the planning scenarios (made by the AESO and us) is to de-rate wind based on its average availability. For instance, the estimated 6,000 MW of wind expected by 2028 produces an average of 2,120 MW of output. ${ }^{19}$ The problem is that this average will not be representative of the variation in energy production in any given hour. To the extent that wind generation from various facilities is positively correlated, the average could be misleading. If the correlation is one, then situations can arise where either all of the wind is available or none of it is available. The AESO in their long-term plan assume that wind is "firmed" after $2018 .^{20}$ Firming means that the average de-rated capacity will always be available.

The alternatives for firming include investment in additional capacity equal to the derated expected capacity. If the HVDC transmission lines are not built this would be gasfired generation in the south. If the HVDC transmission lines proceed this could be coal and/or gas in the north and gas in the south. There are other alternatives to achieve firming of the wind capacity, including storage or expanding the capabilities of the tie line with British Columbia.

Given the AESO's assumptions regarding greenhouse gas offset costs, gas fired generation in the south has lower long-run unit costs and does not require investment in transmission. Hence gas-fired generation in the south is preferred. Even if greenhouse gas offset costs are reduced by 40 per cent this conclusion still holds.

19 AESO Long-term Transmission System Plan - Appendix G, June 2009. The AESO assumes a range of capacity availability for wind, from 27.5 per cent to 37.5 per cent, with an average value of 32.5 per cent. Based on historical wind dispatch, we assume instead a 35 per cent capacity availability. AESO Long-term Transmission System Plan - Appendix G, June 2009 at p. 284: With respect to wind, "It was assumed that an economic energy storage technology would be available to projects built in 2018 and after." 
But if greenhouse gas offset costs fall by more than 40 per cent then the long-run unit costs of coal can be lower than gas-fired generation at sufficiently high capacity factors. For instance if greenhouse gas offset costs are zero, then coal-fired generation has a lower longrun unit cost than combined-cycle gas if the capacity factor is greater than 60 per cent. For greenhouse gas offset costs less than 60 per cent of the AESO's assumed value it may be possible that expanding coal generation in the north and adding transmission capacity would be less expensive to firm up wind than combined-cycle gas in the south. However, we find that this is not the case.

Using coal-fired generation to firm up wind capacity is not likely to be optimal because coal-fired generation is typically baseloaded. ${ }^{21}$ It would be more natural to assume that the choice is between gas-fired capacity in the south and gas-fired capacity in the north plus transmission. In that case, the best choice is gas-fired generation in the south since the generation cost is the same and an expansion of transmission capacity is not required. Another interpretation that makes coal-fired generation in the north a more logical alternative is if wind power is simply not developed. This is an extreme assumption that favours the development of coal in the north and adding transmission capacity.

We consider whether our conclusion regarding the economic efficiency of the proposed HVDC lines is robust to zero greenhouse gas offset costs and no additional wind investment after 2009, assuming variable cost based dispatch. In the unconstrained case, (with the proposed HVDC lines) we assume that coal and gas-fired capacity is added in the north, where we limit the amount of incremental coal generation added so that it operates at a capacity factor of 85 per cent or more. ${ }^{22}$ In the constrained case, (without the proposed HVDC lines) incremental generation in the north is also assumed to be a mix of coal and gas, where we again restrict the capacity factor for the coal plants to be greater than 85 per cent, and is only gas-fired generation in the south. Under these assumptions we find that the NPV of the lower generation costs in the unconstrained case is $\$ 815$ million (\$2008) instead of \$21 million (\$2008). Though this is a large increase in the benefit associated with the two HVDC lines, the NPV of the two HVDC lines is still $\$ 1.1$ billion more than the generation-only solution. It also assumes greenhouse gas offset costs are zero.

(iii) There are advantages to using an independent regulator to assess whether a transmission project is in the public interest. It is less likely that project approval and conditions will be driven by short-term political interests and more likely that the regulator's perspective will reflect long-term benefits and costs to the province. Regulatory agencies typically draw on relevant expertise, historical awareness and background knowledge to understand, evaluate and adjudicate complex issues. A public process allows for greater

21 Baseload generation is normally operated all day to meet baseload demand, the part of load that is relatively constant. Coal-fired generation has low operating costs and high fixed costs, which along with its relative inflexibility makes it ideal to meet baseload demand. Because it is slow to ramp up it is not a good alternative when demand peaks or the wind does not blow as expected.

22 Coal-fired generation is added only if it is utilized at least 85 per cent of the time. If additional capacity is required, but it would not be in operation more than 85 per cent of the time, the additional capacity added is gas-fired. This avoids our results being distorted by adding coal-fired generation to meet peak demand in the north. 
scrutiny of alternative points of view and provides a forum for public debate. The process also requires the regulator, through written decisions, to provide their rationale for each decision. This is an important constraint on the potential for collusion between the decision maker and private interests. These advantages will depend upon the extent to which the regulator is at arm's-length from the government.

There are also disadvantages to following a regulatory process in approving a major transmission project, including the fact that it is often costly and the decisions may not be timely. Unilateral government action on such a decision is likely to provide a superior solution only if there is widespread agreement of a problem, time is of the essence and if the cost of not addressing the problem is far more expensive than exploring alternatives.

Our results, showing that the two proposed HVDC lines are economically inefficient and unwarranted given the AESO's assumptions and forecasts, point to the benefit of a regulatory process, and raise doubts that the state of reliability and supply adequacy indicate the need for an emergency response. Indeed, if an emergency existed, the generation-only solution to manage the transfer constraint on the north-south corridor can be implemented faster than construction of the two HVDC lines. Such conclusions show the benefits of a regulatory process. Even if the existing regulatory process is judged to be dysfunctional or a major hindrance to generation development and expansion of the transmission grid, a better response may be to make changes to that process rather than bypassing it.

\subsection{The Context of the Study and Qualifications}

Given the importance of electricity to the welfare of Albertans, and the political sensitivities to transmission policy, it is important for us to emphasize what this paper does not do and what we do not conclude.

(i) This study is not a critique of the existing market design and institutions in Alberta. It does, however, raise specific questions and concerns about the government's transmission policy in general, and Bill 50 specifically. We illustrate that those concerns might well be material by considering the economics of the two HVDC lines proposed for the Edmonton-Calgary corridor. We do not comment about the three other CTI projects in Bill 50.

There might be other benefits associated with the two HVDC lines not captured by our analysis which would make the economics of these two lines more favourable. In the study we comment on whether reliability or mitigation of market power might be two such benefits. 
The market power concern is that reinforcement of the north-south line is necessary to avoid the exercise of market power in southern Alberta. This is a possibility, though it is not obvious, given the anticipated extent of wind generation and investments required to firm it up. There are two relevant questions. First, is the cost of market power greater than $\$ 1.7$ billion to $\$ 1.9$ billion? The benefit from disciplining market power by installing the two HVDC lines must exceed its cost for market power considerations to justify the two HVDC lines. However, it is not sufficient to conclude that the two HVDC lines are economic because they control market power. The second question that needs to be asked is whether there are other cheaper alternatives to mitigate the development of market power in southern Alberta. If there are, then the two HVDC lines remain uneconomic.

A second suggested benefit is that the two HVDC lines are necessary to meet reliability requirements. It is important to distinguish between the costs of congestion and the costs of unreliability. Our analysis measures the cost of congestion, while maintaining current reliability requirements.

A particular concern is that the development of congestion and/or a more efficient congestion policy in the transmission grid would lead to a redesign of the market that would be costly. While this may or may not be true, it is not sufficient to merely assert that any redesign instituted because of congestion or implementation of a different congestion policy would be costly. Instead it is necessary to show that the costs from redesign would exceed the extra costs associated with the congestion-free policy (e.g., the $\$ 1.7$ billion to $\$ 1.9$ billion incremental cost of the two HVDC lines versus a generation-only solution, but this is only the cost associated with the two HVDC lines proposed for the Edmonton-Calgary corridor, not the incremental cost associated with implementing a congestion-free policy over the entire transmission grid) ${ }^{23}$ Our results simply show that the costs of a congestion-free policy, in terms of the costs of delivered electricity, can be substantial.

Prebuilding transmission in advance to increase investment in generation, strengthening the system to increase intertie capacity, the mitigation of market power, and minimization of land impact and rights of way are examples of other benefits that have been suggested. However, for these considerations to overturn our conclusion that the two HVDC lines are inefficient, it is necessary to establish that the benefits not counted in our analysis are worth more than $\$ 1.7$ billion to $\$ 1.9$ billion, and that those benefits cannot be achieved by a less expensive alternative.

23 It is important to recall that our focus is on the resource cost of providing electricity to Albertans. We do not include the possibility that the current market design if congestion increases, or changes to the market design in response to congestion, would result in large transfers from consumers to generators. We suspect, and would hope, that if congestion or the response to congestion resulted in significant transfers from consumers to generators, the market design would be changed. Otherwise consumers are being asked to incur, in the case of the two HVDC lines, an additional cost of $\$ 1.7$ to $\$ 1.9$ billion to avoid the transfer. As per the discussion in the text, a better response might be to change the market rules or market design. 
(ii) This study does not conclude that the Alberta experience with regulatory restructuring and the introduction of competition and market forces into the AIES is a failure.

(iii) This study does not propose specific policies to address the following:

(a) What should the pricing of transmission be in Alberta?

(b) What should the process be for planning and approval of transmission investment in Alberta?

These are important issues. Given the time and resources available our objective was much simpler: are the two HVDC lines as proposed in Bill 50 good for Albertans or is there at least one alternative that might be better? If so, then it appears to us that the abbreviated and limited scrutiny of this CTI are a disservice to Albertans. Moreover, this study is clearly not the study, but a study. It should lead to additional studies where the answers to these questions can be explored and a debate over the alternatives can proceed in the proper forums.

(iv) We do not conclude that any north-south reinforcement of the transmission grid is inefficient or not required. We do not conclude that a generation-only solution is optimal. A mix of generation and transmission expansion may be optimal. We are not against transmission. We are against transmission projects, like the two HVDC lines that, on the basis of our analysis, cost Albertans $\$ 1.7$ to $\$ 1.9$ billion more than is required. Our conclusion is that the large cost and capacity of the two HVDC lines, 4,000 megawatts, is an overbuild that is not warranted by its economics.

\subsection{Plan of the Study}

Section 2 is a review and analysis of transmission policy in Alberta. Section 3 assesses the two HVDC lines proposed for the Calgary-Edmonton corridor. Section 4 is a short discussion of the advantages of a public regulatory process. 


\subsection{TRANSMISSION AND TRANSMISSION POLICY IN ALBERTA}

This section provides an introduction to the complexity of electricity and why its physical characteristics make regulatory restructuring of electric networks more difficult than other sectors where functions can be physically separated, unlike electricity. It then describes and analyzes the existing regulatory policy and framework for transmission pricing and investment.

\subsection{Electricity is Different}

In order to maintain a reliable electricity system, the balance between demand and supply of electricity must be maintained at every point on the system at all times. Since demand and supply vary constantly and can be unpredictable, this requires continual monitoring and coordination between generation and consumption.

Transmission of electricity is not just transportation. Instead, transmission plays a fundamental role in coordinating the efficient supply of reliable electricity by integrating multiple generation facilities. The separation of transmission from generation is not as straightforward as in gas or telecommunications. In the case of electricity there are important operating complementarities between transmission and generation. In order to keep the network operational, generation decisions cannot be made independently. In addition, there is no direct link between the energy supplied by a single source at one location and the energy consumed at another location. How a particular consumer is served depends on the behaviour of other suppliers and other demands on the electric network.

These considerations mean that there will be network externalities. The capacity and cost of using transmission facilities will depend on the behaviour of others - other suppliers and consumers of electricity. The interaction is sufficiently complicated that defining property rights in transmission and relying only on markets is not likely to result in an efficient and reliable network. There are also important investment complementarities between generation and transmission. The location and size of generating plants are influenced by the interconnections provided by the transmission system. Conversely, the location and amount of generation affects transmission capacity. Changes in transmission capacity can impact both the costs incurred by individual generating units and the value of these generating units. It is the network externalities that mean the economic separation of function is not a physical separation. An electric system is an integrated physical machine.

\subsection{Transmission Policy in Alberta}

Transmission policy with regard to investment and pricing in Alberta has been set by the government. It is detailed in the white paper on transmission policy, Transmission Development: The Right Path for Alberta, and the Transmission Regulation under the Electric Utilities Act. ${ }^{24}$

\footnotetext{
24 Alberta Regulation 86/2007.
} 


\subsubsection{TRANSMISSION PRICING}

The transmission regulatory framework was a response to the Congestion Management Principles decision by the Alberta Energy and Utilities Board (AEUB) in 2002. ${ }^{25}$ Prior to that decision, system transmission costs were allocated (approximately) 50 per cent to load and 50 per cent to generators. ${ }^{26}$ The Electric Utilities Act mandates that transmission rates for load (consumers of electricity) must not differ because of location. Rates that are not a function of location, and hence distance, are known as postage stamp rates. Prior to the Congestion Management Principles decision, the rate design to recover the system transmission costs allocated to generators involved postage stamp rates.

In its Congestion Management decision, the AEUB determined that location-based charges for the recovery of system enhancements was important to ensure incentives were established to minimize the costs of delivered power (i.e., generation and transmission costs). It is worth quoting the AEUB on its rationale: ${ }^{27}$

Most parties agreed that the congestion management principles approved by the Board should have the objective of permitting customers to realize the lowest delivered cost of energy. The Board agrees that the cost of delivered energy is an important objective to be considered in the design of congestion management principles.

As an overriding principle, the Board considers that the development of competitive markets in the deregulated generation and retail sectors coupled with regulated transmission and distribution sectors that harness market forces to the greatest extent possible will maximize the likelihood of achieving an efficient overall cost to customers.

The focus of the congestion management proceeding is on the deregulated generation and the regulated transmission sectors, the combined costs of which, for the purposes of this proceeding, the Board has referred to as the delivered cost of energy. The Board recognizes and acknowledges that this "delivered cost of energy" covers only a portion, albeit a large portion, of the overall cost to customers.

The difficulties of achieving an efficient cost of delivered energy results from the fact that the generation and transmission sectors do not operate independently of each other. For example, a least cost transmission system may limit the development of an efficient generation market. As a consequence, it may not be appropriate to minimize transmission costs if that adversely impacts the development of a more competitive generation market resulting in a higher delivered cost of energy. On the other hand, having no regard to the cost of transmission facilities to accommodate new and existing generation may also result in a higher delivered cost of energy.

25 AEUB Decision 2002-099.

26 System transmission costs can be thought of as the cost of facilities that are shared. They are not specific to interconnecting a generator. See Transmission Development Policy Paper at p. 5. What we refer to as system transmission is sometimes called bulk transmission. The cost allocation between generators and load was implemented in 2000. Under regulation, load was allocated most of these costs.

27 AEUB Decision 2002-099 at pp. 29-30. 
Prior to 1996, central planners attempted to achieve economic and timely expansion of the transmission system in concert with growth in generation and load, with a view to obtaining the lowest cost of reliably delivered energy for consumers. The Board considers that, under restructuring, market forces should be used to the greatest extent possible and central planning should be minimized.

The Board considers it important that transmission rates be designed to facilitate competition and promote economic siting decisions by generators. The Board is of the view that the best way of achieving these objectives is to provide individual generators with appropriate locational transmission cost signals, and then let the market deliver the resulting lowest combined cost of generation and transmission.

The Board considers that the pricing signals should be fair, transparent, and predictable so as to minimize interference in the generation market and provide generation investors with a reasonable degree of regulatory certainty.

In summary, by providing generators with appropriate transmission cost signals, the market is expected to deliver the lowest delivered cost of energy to customers.

The AEUB directed the Transmission Administrator (TA) to file location-based tariffs under which the generators' share of all system upgrades would be recovered by zonal interconnection charges on generators in zones that benefited from the expansion in transmission. ${ }^{28}$ These were demand charges (i.e., fixed $\$ / \mathrm{MW}$ ), intended to send strong locational signals to generators. ${ }^{29}$

The government responded with its transmission policy which reversed location-based pricing. Indeed, it went further, allocating all system costs to load. The reversal was based on the premise that transmission should be unconstrained, facilitating investments in generation and competition in the energy market..$^{30}$

The Transmission Regulation sets out the government's policy with respect to transmission pricing: ${ }^{31}$

(i) Generators are charged their local interconnection costs, must bear location-based line losses and are required to make a contribution to system upgrades.

(ii) All other costs are recovered through postage stamp tolls on load.

\footnotetext{
28 The Transmission Administrator (TA) was responsible for the planning and operation of the transmission grid under amendments to the Electric Utilities Act in 1998. Amendments in 2003 abolished the TA and rolled its functions into the Power Pool, creating the Alberta Electric System Operator.

29 AEUB Decision 2002-099 pp. 83-85.

30 See “Minister Proposes Transmission Policy," IPPSA News 9(3) at p. 3, 2003.

31 See in particular, Section 47.
} 


\section{Analysis of Transmission Pricing Policy and Regulation in Alberta: Locational Signals}

The price of system access should reflect the costs of providing service. In the short run, there are two marginal costs associated with providing transmission service. These are line losses and the costs of congestion. The costs of congestion are the costs of re-dispatch. The costs of re-dispatch are the difference between the costs of the in-merit generator and the costs of the higher cost, out-of-merit generator that replaces it because of the transmission constraint. ${ }^{32}$ In the long run, the costs of the grid (i.e., the cost of the facilities required to provide service), must be recovered.

Three provisions of the Transmission Regulation appear to suggest some location-based elements to the transmission pricing framework. These are local interconnection costs, line losses and system contribution. In addition, there are non-tariff locational signals. These include congestion and delays in being connected, which are not intended to provide locational signals. The objective of the transmission policy is a congestion-free transmission system where generators are able to connect without constraint on the ability to provide energy. While generators are responsible for their local interconnection charges, the debate over locational signals is not about local interconnection costs, but rather allocation and recovery of system transmission costs.

Under the Generator System Contribution requirement, new generators are required to pay a per MW charge for interconnection that depends upon their location. The province is divided into six regions. For all regions, there is a base charge of $\$ 10,000 / \mathrm{MW}$. In regions where generation exceeds load, there is an additional charge that can be as high as $\$ 40,000 / \mathrm{MW}^{33}$

Line losses are energy losses due to heat from resistance to electrical current flow on the transmission lines. As power flow increases, the line losses also increase. As more power moves from one area on the transmission grid to another, line losses will increase. Generators that locate in a region that is already making heavy use of the transmission grid will impose higher line losses on the system than if they locate in a region where the system is used less intensively. Since generators in Alberta pay the cost of line losses, it has been argued that line losses provide an adequate locational signal.

The effectiveness of the two pricing mechanisms that might send a locational signal with respect to system transmission costs, Generator System Contribution and line losses, has been questioned. There are two reasons why the strength of the location-based signal provided by the Generator System Contribution is very weak. First, the highest possible fee, $\$ 50,000 / \mathrm{MW}$, is a very small fraction of the estimated cost of constructing a power plant. ${ }^{34}$ Second, the Generator System Contribution is refundable over the 10-year period after commercial operation date. The refund involves an annual payment back to the generator if it met its annual capacity factor target for that year. Failure to meet the annual capacity factor forfeits that year's refund. If the generator meets all of its annual capacity factor targets it recovers all of its system contribution. Though generator system contribution is intended to provide a means to recover the costs of shared facilities, it does not in fact do so.

32 This is also the lost profit of the marginal out-of-merit unit in the low-cost region not sold because of the transmission constraint. Hence, it is the opportunity cost of the marginal unit in-merit in the low-cost region.

33 See AESO, Generator System Contribution Policy, February 11, 2009 for details.

$34 \$ 50,000 / \mathrm{MW}$ is just over 1.5 per cent of the AESO's estimated "overnight" capital cost of constructing a brownfield coal plant. See AESO Long-term Transmission System Plan, June 2009, at p. 251,

http://www.aeso.ca/downloads/AESO_LTTSP_Final_July_2009.pdf. A brownfield coal plant is located at an existing site and hence has lower costs than a plant located at a new site (a greenfield plant). 
It has also been argued that the implementation of the location-based line loss charges is not very effective. ${ }^{35}$ Among other things, the Transmission Regulation places significant constraints on the extent to which line loss charges can vary across locations. When coupled with the relatively small size of all line losses, this casts considerable doubt on the effectiveness of present line loss charges to influence the location decisions of generators. Moreover, there is an inherent contradiction in expecting line losses to guide location decisions when a key factor used to assess whether expansion of the transmission grid is in the public interest is high line losses. It is doubtful generators will avoid locations with high line losses. A policy of zero congestion on the transmission grid further undercuts the use of line losses as a locational signal because generators know that constraints must be relieved, and when they are, their loss charges will decline. ${ }^{36}$

Line losses are not really an appropriate instrument, in any event, for guiding location decisions. Location decisions are "long-run" and involve the expenditure of significant sunk capital, whereas line loss costs are volatile and difficult to predict without knowledge of where future generators will locate on the system. The addition of even small generators at many locations can cause substantial changes in the line loss costs at that location and at nearby locations. Line loss costs are not sufficiently predictable or stable enough to be factored into decisions of where to place generation sites. They do not reflect the costs of shared facilities or congestion costs.

Existing tariffs for access to the transmission grid fail to promote the efficient of the grid in the short run since they do not reflect marginal line losses and congestion costs. And because they do not reflect the long-run costs of providing service to a location, they fail to promote the efficient development of the grid and efficient location of generators.

\section{Analysis of Transmission Pricing Policy and Regulation in Alberta: Implications}

The costs of system transmission are primarily recovered through postage stamp tolls paid by load. This means that the AESO cannot discriminate by customer location and that the share of system transmission costs recovered from generators is minimal. Moreover, the share of system transmission costs recovered from generators is not recovered through a tariff that provides a strong signal that reflects the impact on system costs of a generator's location decision. Generators face a price for system access that is only faintly reflective, if at all, of the costs they impose on the bulk transmission system. Generators located far from load and those that create congestion on the grid will impose higher costs on the system or bulk transmission grid than generators located close to load and that do not create congestion.

35 See ENMAX, Fostering the Efficient Development of Alberta's Electricity Infrastructure through Changes to the Transmission Regulation, May 2008, and G. Angevine and A. Boik, Alberta Electricity Transmission Policy for the Next Generation, Fraser Institute Studies in Energy Policy, March 2009.

36 An indication that loss charges are not providing an effective locational signal is provided by the draft loss factors for 2010. These show that the loss charges to the generators that are most often dispatched to resolve congestion using Transmission Must Run (TMR) (the Rainbow and Fort Nelson generators) are in fact higher than the system average loss charges and in the case of Fort Nelson are the highest charges to any generator in the system. See AESO Operating Policies and Procedures Transmission OPP 501 at http://www.aeso.ca/downloads/OPP_501.pdf and AESO Draft Loss Factors for 2010 at http://www.aeso.ca/downloads/Draft_Loss_Factor_2010.pdf. 
The consequence of having system access prices for generators that are small and not reflective of transmission costs is that competition among generators will essentially minimize the costs only of generation (which can be thought of as including the direct costs of interconnection to the grid). Generators can locate in large part independent of system transmission costs because those costs are borne by load. The existing transmission pricing policy could easily create excessive demand for expansion of system transmission facilities to serve lower-cost generation that is far from load, and result in a competitive disadvantage for generation located closer to load. The result would be an inefficient mix of transmission and generation assets, raising the total costs (generation and transmission) of the AIES that must be recovered from load or, in other words, Albertans.

An important policy objective should be a regulatory structure that results in the minimization of the total cost of delivered electricity. ${ }^{37}$ This involves minimizing the sum of generation and transmission costs (as well as external costs such as environmental damage), where transmission costs include both the costs of congestion and transmission facilities. The problem with not having locational pricing signals tied to the costs that are imposed on the transmission system is that it results in a subsidy to high-transmission cost generation: generation that would not be competitive if it had to recover the costs it imposes on the grid. Consequently, the present transmission policy can lead to distortions in the price of electricity.

While it is true that in a competitive market, the ultimate incidence of all costs falls on consumers, the magnitude of the costs so borne is not exogenous. Rather it depends upon who pays the cost of transmission. If generators pay the incremental cost they impose on the system, then they have incentives to minimize their total costs of supply, both transmission and generation. If load pays any incremental costs of transmission created by a generator, generators no longer have incentives to minimize the cost of transmission, resulting in higher total costs.

\subsubsection{TRANSMISSION INVESTMENT}

The Transmission Regulation specifies "robustness" requirements that impose a design standard on the transmission grid for the AESO. ${ }^{38}$ The standard has two components. First, under normal operating conditions, "all anticipated in-merit" generation can be dispatched 100 per cent of the time when all transmission facilities are in service. Second, at least 95 per cent of the time "all anticipated in-merit" generation can be dispatched under abnormal operating conditions (i.e., when some transmission facilities are not available). The Transmission Regulation makes it

\footnotetext{
While maintaining acceptable levels of reliability. If this objective is not met, there will be pressure for institutional and market reform.

38 Transmission Regulations at 15(1)(e) and (f).
} 
clear that the ability of the AESO to resort to "non-wire" solutions to meet the demand of load is limited. In accordance with the Transmission Policy paper, the government's objective is congestion-free transmission. ${ }^{39}$

Before Bill 50, the regulatory approval process for new transmission investment involved the following:

(i) The AESO is required by Section 34 of the Electric Utilities Act to prepare and submit a Needs Identification Document (NID) to the AUC. This document presents the AESO's case for why the transmission enhancement or expansion is necessary to alleviate a constraint, improve efficiency and reduce line losses, or respond to requests for system access.

(ii) The AUC can approve, deny, or send the NID back for revision. If the AUC agrees that the transmission enhancement or expansion is necessary to alleviate a constraint, improve efficiency and reduce line losses, or respond to requests for system access, it must then determine whether approval is in the public interest as required by Section 17 of the Electric Utilities Act. ${ }^{40}$ Section 38 of the Transmission Regulation instructs the AUC to look favourably on transmission investments that foster a competitive generation market, or contribute to its robustness by noting that these effects are in the public interest. The AUC is to consider the AESO's assessment as correct unless an intervener demonstrates a technical deficiency or if approval of the NID would not be in the public interest. This is a significant hurdle for interveners since they seldom have access to the same level of information or resources as the AESO.

39 It is worth highlighting the government's presentation of its robustness criteria in the Transmission Development Paper (at p. 8). This makes clear that the government expects the AESO will plan and oversee the development of a transmission grid in which congestion is rare:

The open access transmission structure in Alberta consists of an implicit system of injection and withdrawal rights for generators and loads. There are no explicit transmission rights. Given this structure, the transmission system must be relatively congestion free or the underlying market model will not function effectively.

The ISO must therefore proactively plan transmission development to achieve this result of "congestion-free" transmission. The ISO will be required to ensure that the transmission system internal to Alberta is appropriately reinforced so that under normal operating conditions (i.e. all transmission facilities in service) all in-merit generation can be dispatched and virtually all economic wholesale transactions may be realized without congestion.

Given the lumpiness of transmission additions, the $95 \%$ criterion is intended to be a guideline and not an absolute number. Congestion may occur during planned maintenance, forced outages of transmission facilities and/or some critical generation facilities. It is also essential that the transmission system be sufficiently robust to allow timely and appropriate maintenance of transmission facilities.

In our market model, it is critical in the relatively few cases where transmission constraints are not removed, real time congestion arrangements should not set or distort market prices. [Emphasis added.]

40 See AUC Decision 2009-126. 
(iii) Section 34 approval triggers an application by the Transmission Facilities Owner (TFO) for facility approval under the Hydro and Electric Energy Act (HEEA). Section 19 of the HEEA gives the AUC the power to require changes in the plans, specifications or location of a transmission line, and to prescribe the location, route and extent of right-ofway for a transmission line.

\section{Analysis of Transmission Investment Regulation in Alberta: The Zero-Congestion Fallacy ${ }^{41}$}

Given the importance of the congestion-free policy, it is important to understand why it is inefficient. Transmission lines are examples of facilities where demand is not constant, but variable. ${ }^{42}$ Transmission lines have two characteristics that preclude the ability to adjust capacity to meet demand by increasing it in peak periods and decreasing it in off-peak periods. These are capital intensity and specificity. Capital intensity implies that efficient additions to capacity require time. Specificity relates to the fact that transmission lines, like other major infrastructure, are a capital investment that cannot be redeployed for another use. These characteristics are important because electricity is not (easily) storable creating the following dilemma. Capacity installed to meet peak period demand would not be used in off-peak periods. On the other hand, while reductions in capacity reduce the costs of providing service, they also result in congestion problems during peak periods. ${ }^{43}$ That is, in peak periods transmission is congested and some generators may not be able to supply all the power they wish. Instead, out-of-merit, higher-cost local generators will be dispatched, giving rise to congestion costs. The optimal level of capacity will trade off the costs of unused capacity in off-peak periods against the congestion costs from not having sufficient capacity during peak periods. At the optimal level of capacity, the marginal cost of capacity will equal the costs of congestion eliminated by the marginal unit of capacity.

To have a congestion-free system, transmission capacity must be installed to meet the peak demand of generators. However, most of the time demand for transmission capacity will be less and the marginal transmission capacity will hardly ever be used. Still, it must be paid for. This is likely never efficient: the cost of the extra transmission capacity is likely more than the congestion costs.

Steven Stoft observes that one of the reasons zero congestion sounds attractive as a policy goal is because of confusion between congestion and unreliability. ${ }^{44}$ In a congested system, load downstream of the transmission line that is constrained are served by more expensive local generation. A system is unreliable if downstream of the constrained transmission line, local generation is insufficient to meet load and some customers have to reduce their use of electricity. The costs of unreliability are much more since load must be rationed: the costs of rationing are the lost profits or consumption benefits from reducing electricity use. It is the costs of congestion, not unreliability, that we focus on in our analysis of the economics of the two HVDC lines in the next section of this study. The two alternatives we compare, the two HVDC lines and a generation-only solution, both meet current reliability requirements.

\footnotetext{
${ }^{41}$ See S. Stoft (2006), "Problems of Transmission Investment in a Deregulated Power Market," Competitive Electricity Markets and Sustainability, ed. F. Leveque, Northampton, Mass.: Edward Elgar, pp. 87-130.

42 The following is based on J. Church and R. Ware (2000), Industrial Organization: A Strategic Approach, New York: McGraw-Hill, Section 25.3.

43 We ignore line losses in this discussion for simplicity.

44 See S. Stoft (2006), "Problems of Transmission Investment in a Deregulated Power Market," Competitive Electricity Markets and Sustainability, ed. F. Leveque, Northampton, Mass.: Edward Elgar, pp. 87-130.
} 
The congestion-free transmission policy suggests three hypotheses:

(i) The zero congestion policy precludes efficient substitution between transmission (wire) solutions and non-wire (generation and/or load response) solutions. That is, it doesn't contribute to minimizing the total cost of delivered electricity, but only the cost of generation. It explicitly appears to reject that a higher-cost generation unit with lower-cost transmission may be preferred over a lower-cost generator with higher transmission costs.

(ii) Second, the bias towards transmission wires is done in a particularly costly way by mandating that all in-merit generation be dispatched (i.e., not constrained down), under virtually all conditions, including peak north-south flows.

(iii) Third, the mandate for a congestion-free transmission grid ignores that the costs of attaining that objective might be greater than the benefits.

Bill 50

Bill 50 introduces the following changes:

(i) The requirement under Section 17 of the Alberta Utilities Commission Act requiring the AUC to consider the public interest under the Hydro and Electric Energy Act does not apply to CTI. Moreover, Section 19 of the Hydro and Electric Energy Act is amended to make it explicit that the AUC cannot refuse approval of a transmission line deemed CTI "on the basis that, in its opinion, the project does not meet the needs of Alberta or is not in the public interest."

(ii) Section 34 of the Electric Utilities Act does not apply to CTI. Instead, these transmission facilities are approved or designated by the government and the AESO must follow up by ensuring that an application is made to the regulator for approval under the Hydro and Electric Energy Act.

\subsubsection{CONCLUSION}

Our analysis suggests the following predictions:

(i) It is likely that there will be demand for transmission expansion for which the costs outweigh the benefits.

(ii) The result will be an electric system that has an inefficient mix of generation and transmission, leading to a higher-than-necessary cost of delivered electricity.

(iii) The logic of equating the public interest with congestion-free transmission is inefficient.

Our analysis of Bill 50 in the next section is consistent with these three hypotheses. We demonstrate the magnitude of the inefficiency by showing that the costs of the two HVDC lines mandated as CTI under Bill 50 far exceed our estimates of their benefit. 


\subsection{ASSESSING THE TWO HVDC LINES IN THE EDMONTON-CALGARY CORRIDOR}

In this section we compare the costs of a generation-only solution with the proposed two HVDC lines deemed critical between Edmonton and Calgary. We begin with a brief review of the AESO's application for reinforcement in 2004, followed by a discussion of our methodology. The next part discusses assumptions and is followed by a cost comparison of the cost of generation re-dispatch and gas-fired generation expansion in the south to coal-fired generation expansion in the north combined with the proposed HVDC transmission reinforcement. A final part discusses other relevant considerations and qualifications.

\subsection{Transmission Reinforcement in the Edmonton-Calgary Corridor}

The need for transmission reinforcement between Edmonton and Calgary was anticipated in 2004 when the AESO filed an Edmonton-Calgary $500 \mathrm{kV}$ Transmission Development Need Application. ${ }^{45}$ In that application, the AESO forecast a need for transmission reinforcements arising in 2009. Thirteen alternative transmission reinforcements were evaluated as potential solutions. Capital costs (in \$2004) of these alternatives ranged from a low of \$359 million to a high of $\$ 766$ million. The lowest capital cost was for two double circuit $240 \mathrm{kV}$ lines between Edmonton and Calgary. The highest capital cost was for a $500 \mathrm{kV}$ HVDC line with 1,500 MW of transfer capability. The AESO's preferred option was to build two $500 \mathrm{kV}$ AC transmission lines between Edmonton and Calgary at an estimated capital cost of $\$ 553$ million. This alternative received regulatory approval in 2005, but the authorization was subsequently voided in 2007. The AESO has indicated that since the 2004 application, system improvements and lower than forecasted rates of load growth have delayed the anticipated need for reinforcement of the Edmonton to Calgary transmission path to $2014 .^{46}$

In its 2004 need application, the AESO indicated that no technical studies of HVDC (high voltage direct current) transmission were carried out because the technology was considered more expensive than alternating current (AC) solutions for medium distance applications such as the 300-kilometre path from Edmonton to Calgary. ${ }^{47}$ In its 2009 Long-term Transmission System Plan, the AESO also discusses HVDC transmission, noting that "DC for overhead lines is generally more economic than $\mathrm{AC}$ when the transmission distance is greater than 700 kilometres $(\mathrm{km}) .{ }^{48}$

The two $500 \mathrm{kV}$ HVDC transmission lines currently proposed are estimated to cost $\$ 3.135$ billion (\$2008). In 2004, the AESO's preferred alternative to meet the anticipated need for north-south transmission was to build two $500 \mathrm{kV}$ AC transmission lines between Edmonton and Calgary at less than one-fifth the cost in real dollars (approximately \$590 million (\$2008)).

\footnotetext{
45 Edmonton-Calgary 500 kV Transmission Development - Need Application No:1346298, May 7, 2004.

${ }^{46}$ AESO Long-term Transmission System Plan - Edmonton to Calgary transmission reinforcements - p. 6, June 2009, http://www.aeso.ca/downloads/AESO_LTTSP_Final_July_2009.pdf, Accessed Sept. 23, 2009.

${ }^{47}$ Edmonton-Calgary $500 \mathrm{kV}$ Transmission Development - Need Application No: 1346298, Section 4.3.2 - Technical Evaluation, p. 44, May 7, 2004.

48 AESO Long-term Transmission System Plan — Appendix I, June 2009, http://www.aeso.ca/downloads/AESO_LTTSP_Final_July_2009.pdf, Accessed Sept. 23, 2009.
} 


\subsection{Study Methodology}

The proposed HVDC transmission reinforcements between Edmonton and southern Alberta are expected to enter service in $2013 .^{49}$ It is assumed that these reinforcements will resolve any further congestion until 2028. This study compares the NPV of costs between 2013 and 2028 for the proposed north-south HVDC transmission upgrades, unconstrained generation dispatch and pattern of generation expansion with those for constrained generation dispatch and pattern of generation expansion without the transmission upgrades to the north-south path. The two cases considered are:

\section{(i) Bill 50 [Unconstrained]}

Under this case, the two HVDC lines are built, adding 4,000 MW of transmission capacity and we assume that transmission is unconstrained. Incremental generation is coal-fired and added to the north.

\section{(ii) Generation Only [Constrained]}

In this case, transmission capacity in the north-south corridor remains at current levels. Initially all new generation capacity is assumed to be coal added in the north. Dispatch is assumed to be unconstrained and the resultant north-south power flows are determined. If the power flows exceed the current threshold limit, the province is split into a northern region and a southern region. Each region is then re-dispatched based on its own dispatch order such that the maximum north-south flow is not exceeded. New generation is only required in the south if the north-south flows required to meet load exceed the maximum threshold value.

In order to focus on the relative cost of the two solutions in addressing the expected transmission congestion, we assume that the AESO's expected supply adequacy requirement is met in both cases. As the AESO notes, generation in Alberta is not planned, but competitive, and there is not a regulated requirement for a reserve margin. Instead the AESO expects that market signals will operate to ensure there is an Effective Reserve Margin (ERM) of 10 per cent. ${ }^{50}$ The ERM is calculated as the ratio of the sum of the installed thermal generation capacity, 20 per cent of the installed wind and irrigation hydro capacity, 33 per cent of the legacy hydro, and 50 per cent of new hydro capacity to the annual peak Alberta Internal Load (AIL), minus one. The current ERM is approximately 16.3 per cent.

The modeling exercise has three components:

(i) Dispatch Model. The dispatch model selects the generation assets that are dispatched to meet load.

\footnotetext{
49 AESO Long-term Transmission System Plan — Executive Summary, June 2009, http://www.aeso.ca/downloads/AESO_LTTSP_Final_July_2009.pdf, Accessed Sept. 23, 2009.

50 AESO Long-term Transmission System Plan — Appendix E, June 2009, http://www.aeso.ca/downloads/AESO_LTTSP_Final_July_2009.pdf, Accessed Sept. 23, 2009. The ERM is a measure of installed generating capacity above forecast peak load for a year.
} 
(ii) Power Flow Model. The power flow model used was obtained from the AESO. To study the effects on north-south transfers only, increases in system load from 2008 were assigned to either the $500 \mathrm{kV}$ bus at Genesee in the north or the $240 \mathrm{kV}$ bus at the Janet substation near Calgary in the south. System load increases are apportioned to either the north or south buses based on the existing split between south area and north area loads in the province. Similarly, new generation additions in all simulations are assigned to either the $500 \mathrm{kV}$ bus at Genesee in the north or the $240 \mathrm{kV}$ bus at Janet near Calgary in the south. By aggregating the load and generation increases at these two buses, transmission congestion issues extraneous to the Edmonton-Calgary corridor are eliminated from consideration.

The interaction of the dispatch and power flow model determines the magnitude and location of incremental generation. Given target capacity, generation is added, while the power flow model determines in which region and what type of capacity is added.

(iii) Cost Model. For each case, we estimated the annual variable costs of generation based on dispatch (other than wind and hydro which are common to all cases). We also calculated the annual fixed costs for incremental generation capacity, since existing capacity and that under construction is common across all cases. The costs (in \$2008) calculated for each year are discounted back to 2008 .

\subsection{Assumptions}

To the extent possible, the assumptions we make track those made by the AESO in its longterm plan. This section discusses the nature and rationale of the assumptions underlying the analysis.

\subsubsection{LOAD GROWTH AND PROFILE}

The need for transmission reinforcements and new generation is predicated on a forecast of growing load. Higher rates of load growth mean transmission reinforcements and generation additions are needed sooner. Lower rates of load growth mean the need for transmission reinforcements and generation additions may be delayed.

Historical annual energy (MWh) and peak demand (MW) values for the Alberta Internal Load (AIL) and the Alberta Interconnected Electric System (AIES) load between 2000 and 2007 are given in the AESO's Long-term Transmission System Plan. ${ }^{51}$ The AIL load represents all Alberta consumers, while the customer demand on the transmission grid (the AIES load) is lower because it subtracts the so-called "behind-the-fence load" that is served locally by on-site generation.

51 AESO Long-term Transmission System Plan - Appendix C, June 2009, http://www.aeso.ca/downloads/AESO_LTTSP_Final_July_2009.pdf, Accessed Sept. 23, 2009. 
Growth figures given in the Long-term Transmission System Plan show that from 2003 to 2007, AIL energy grew between 0.4 per cent and 4.6 per cent per year. AIL peak demand over the same period grew between 0.5 per cent and 3.7 per cent per year. Annual energy growth for the transmission grid (AIES load) from 2003 to 2007 varied between 0.47 per cent and 3.1 per cent. Growth in AIES peak demand over the same period varied between 0.6 per cent and 3.4 per cent per year. The most recent load growth figures show that between 2006 and 2007 AIL energy grew by 0.4 per cent and peak demand grew by 0.5 per cent, while AIES energy load grew by 0.47 per cent and AIES peak demand grew by 0.6 per cent.

Hourly load values for the AIL in 2008 and year-to-date 2009 are available from the AESO's website. ${ }^{52}$ These numbers show that energy load growth in 2008 over 2007 was 0.4 per cent. However, 2008 was a leap year. On a normal year basis, the load growth in 2008 was 0.1 per cent. Peak demand in 2008 grew by 0.4 per cent over 2007. From Jan. 1 to Aug. 1, 2009, the data shows that the AIL declined on a year-over-year basis at an annual growth rate of -0.2 per cent. This is summarized in the Table 1 .

TABLE 1

AlL Load 2003-August 2009

\begin{tabular}{|l|c|c|c|c|}
\hline Year & $\begin{array}{c}\text { Energy } \\
\text { (GWh) }\end{array}$ & Growth & $\begin{array}{c}\text { Peak Demand } \\
\text { (MW) }\end{array}$ & Growth \\
\hline 2003 & 62716 & $5.5 \%$ & 8967 & $4.6 \%$ \\
\hline 2004 & 65259 & $4.1 \%$ & 9236 & $3.0 \%$ \\
\hline 2005 & 66268 & $1.5 \%$ & 9580 & $3.7 \%$ \\
\hline 2006 & 69371 & $4.7 \%$ & 9661 & $0.8 \%$ \\
\hline 2007 & 69660 & $0.4 \%$ & 9710 & $0.5 \%$ \\
\hline 2008 Act & 69946 & $0.4 \%$ & 9806 & $1.0 \%$ \\
\hline 2008 Adj & 69746 & $0.1 \%$ & 9806 & $1.0 \%$ \\
\hline 2009 YTD & 42178 & $-0.2 \%$ & - & - \\
\hline
\end{tabular}

AIES Load 2003-2007

\begin{tabular}{|l|c|c|c|l|}
\hline Year & $\begin{array}{c}\text { Energy } \\
\text { (GWh) }\end{array}$ & Growth & $\begin{array}{c}\text { Peak Demand } \\
\text { (MW) }\end{array}$ & Growth \\
\hline 2003 & 53169 & $-0.9 \%$ & 7650 & $1.3 \%$ \\
\hline 2004 & 54669 & $2.8 \%$ & 7910 & $3.4 \%$ \\
\hline 2005 & 55697 & $1.9 \%$ & 8066 & $2.0 \%$ \\
\hline 2006 & 57433 & $3.1 \%$ & 8177 & $1.4 \%$ \\
\hline 2007 & 57701 & $0.5 \%$ & 8228 & $0.6 \%$ \\
\hline
\end{tabular}

The AESO's 2007 and 2008 forecast of load growth are given in Appendix C of their Longterm Transmission System Plan. The growth rates in the 2007 forecast are lower than the 2008 forecast but these both show increasing growth in both energy and peak demand between 2009 and 2012. For this study, we adopted the AESO's 2007 forecast of AIES load growth shown in Table 3.1-1 of the Long Term Transmission System Plan and chose 2009 as the base year. The base year consists of actual hourly recorded loads for the first 32 weeks of the year, while for the last 20 weeks, the 2008 actual values have been inflated by the AESO's forecast growth rate. Future loads are determined by applying the AESO's forecast of annual percentage growth in energy and peak demand load for the AIES load. The resulting forecast of AIES energy and peak demand is shown in Appendix A.

The load profile for a year is created by mapping each of the 8,760 hours of the year into one of 12 cases. The 12 cases are high, medium and low loads for each of the four seasons, winter, spring, summer and fall. 


\subsubsection{COST ASSUMPTIONS}

In the recent Long-term Transmission System Plan the AESO has provided a table of Levelized Unit Electricity Costs (LUEC) for different types of generation. ${ }^{53}$ This table breaks out capital costs, operating and maintenance (O\&M) costs, fuel costs, greenhouse gas (GHG) offset costs, and taxes. Elsewhere, the AESO has provided the heat rates and capacity factors assumed for each generation type. ${ }^{54}$ As well, the AESO has provided a breakout between fixed and variable O\&M costs by generation type. ${ }^{55}$ Relevant parts of the AESO's tables are reproduced in Table 2 below.

TABLE 2

\begin{tabular}{|c|c|c|c|c|c|c|}
\hline Generation Type & $\begin{array}{c}\text { Simple } \\
\text { Cycle }\end{array}$ & $\begin{array}{c}\text { Combined } \\
\text { Cycle }\end{array}$ & $\begin{array}{c}\text { Co- } \\
\text { Generation }\end{array}$ & $\begin{array}{c}\text { Super-Critical } \\
\text { Pulverized } \\
\text { Coal after } \\
2011\end{array}$ & $\begin{array}{l}\text { Integrated } \\
\text { Gasification } \\
\text { Combined } \\
\text { Cycle }\end{array}$ & $\begin{array}{c}\text { Super-Critical } \\
\text { Pulverized } \\
\text { Coal Before } \\
2012\end{array}$ \\
\hline Capacity Factor & 0.1 & 0.6 & 0.9 & 0.92 & 0.8 & 0.92 \\
\hline Capital Cost (\$/MWh) & $\$ 94.00$ & $\$ 23.00$ & $\$ 16.00$ & $\$ 34.00$ & $\$ 51.00$ & $\$ 33.00$ \\
\hline 0\&M Costs Fixed (\$/MWh) & $\$ 15.00$ & 3.00 & $\$ 2.00$ & $\$ 5.00$ & $\$ 7.00$ & $\$ 5.00$ \\
\hline 0\&M Costs Variable (\$/MWh) & $\$ 4.00$ & 4.00 & $\$ 4.00$ & $\$ 6.00$ & $\$ 7.00$ & 6.00 \\
\hline Fuel Costs (\$/MWh) & $\$ 74.00$ & $\$ 53.00$ & $\$ 47.00$ & $\$ 10.00$ & $\$ 16.00$ & $\$ 10.00$ \\
\hline Heat Rate (Gj/MWh) & 9.8 & 7.1 & 6.3 & - & - & - \\
\hline Implied Average Real Gas Price ( $\$ / G j)$ & $\$ 7.55$ & 7.46 & $\$ 7.46$ & - & - & - \\
\hline GHG Offset Costs (\$/MWh) & $\$ 6.00$ & 1.00 & $\$(4.00)$ & $\$ 29.00$ & $\$ 24.00$ & 8.00 \\
\hline Taxes (\$/MWh) & $\$ 23.00$ & $\$ 4.00$ & $\$ 2.00$ & $\$ 8.00$ & $\$ 6.00$ & $\$ 8.00$ \\
\hline Total (\$/MWh) & $\$ 216.00$ & $\$ 88.00$ & $\$ 67.00$ & $\$ 92.00$ & $\$ 111.00$ & $\$ 70.00$ \\
\hline Total without Taxes (\$/MWh) & $\$ 193.00$ & $\$ 84.00$ & $\$ 65.00$ & $\$ 84.00$ & $\$ 105.00$ & $\$ 62.00$ \\
\hline
\end{tabular}

All types of generation incur both fixed and variable costs. The LUEC averages annual fixed costs over the annual energy output from the generator. A key determinant of the LUEC for different types of generation is the capacity factor assumed. The capacity factor represents the energy produced from a generator as a fraction of the maximum possible energy produced over a period such as a year. As the capacity factor increases, the LUEC decreases for every type of generation.

In Table 2, capital costs, fixed O\&M costs and taxes are fixed costs. Variable O\&M, fuel costs and greenhouse gas offset costs are variable costs. If the assumed capacity factor is changed to equal one for all generator types, then the levelized total annual fixed costs per MW of capacity are equal to the sum of the levelized fixed costs multiplied by the number of hours in a year $(8,760)$. Table 3 below shows these calculations.

\footnotetext{
53 AESO Long-term Transmission System Plan - Appendix E, p. 255, June 2009, http://www.aeso.ca/downloads/AESO_LTTSP_Final_July_2009.pdf, Accessed Sept. 23, 2009.

54 AESO Long-term Transmission System Plan - Appendix E, p. 250, June 2009, http://www.aeso.ca/downloads/AESO_LTTSP_Final_July_2009.pdf, Accessed Sept. 23, 2009.

55 AESO Long-term Transmission System Plan - Appendix E, p. 252, June 2009, http://www.aeso.ca/downloads/AESO_LTTSP_Final_July_2009.pdf, Accessed Sept. 23, 2009.
} 
TABLE 3

\begin{tabular}{|c|c|c|c|c|c|c|}
\hline Generation Type & $\begin{array}{l}\text { Simple } \\
\text { Cycle }\end{array}$ & $\begin{array}{c}\text { Combined } \\
\text { Cycle }\end{array}$ & $\begin{array}{c}\text { Co- } \\
\text { Generation }\end{array}$ & $\begin{array}{c}\text { Super-Critical } \\
\text { Pulverized } \\
\text { Coal after } \\
2011\end{array}$ & $\begin{array}{l}\text { Integrated } \\
\text { Gasification } \\
\text { Combined } \\
\text { Cycle }\end{array}$ & $\begin{array}{c}\text { Super-Critical } \\
\text { Pulverized } \\
\text { Coal Before } \\
2012\end{array}$ \\
\hline Capacity Factor & 1 & 1 & 1 & 1 & 1 & 1 \\
\hline Capital Cost (\$/MWh) & $\$ 9.40$ & $\$ 13.80$ & $\$ 14.40$ & $\$ 31.28$ & $\$ 40.80$ & $\$ 30.36$ \\
\hline 0\&M Costs Fixed (\$/MWh) & $\$ 1.50$ & $\$ 1.80$ & $\$ 1.80$ & $\$ 4.60$ & $\$ 5.60$ & $\$ 4.60$ \\
\hline 0\&M Costs Variable (\$/MWh) & $\$ 4.00$ & $\$ 4.00$ & $\$ 4.00$ & $\$ 6.00$ & $\$ 7.00$ & $\$ 6.00$ \\
\hline Implied Average Real Gas Price (\$/Gj) & $\$ 7.55$ & 7.46 & $\$ 7.46$ & - & - & - \\
\hline Heat Rate (Gj/MWh) & 9.8 & 7.1 & 7.1 & - & - & - \\
\hline Fuel Costs (\$/MWh) & $\$ 74.00$ & $\$ 53.00$ & $\$ 53.00$ & $\$ 10.00$ & $\$ 16.00$ & $\$ 10.00$ \\
\hline GHG Offset Costs (\$/MWh) & $\$ 6.00$ & $\$ 1.00$ & $\$(4.00)$ & $\$ 29.00$ & $\$ 24.00$ & $\$ 8.00$ \\
\hline Taxes (\$/MWh) & $\$ 2.30$ & $\$ 2.40$ & $\$ 1.80$ & $\$ 7.36$ & $\$ 4.80$ & $\$ 7.36$ \\
\hline Total (\$/MWh) & $\$ 97.20$ & $\$ 76.00$ & $\$ 71.00$ & $\$ 88.24$ & $\$ 98.20$ & $\$ 66.32$ \\
\hline Total Annual Fixed Costs \$/MW & $\$ 115,632.00$ & $\$ 157,680.00$ & $\$ 157,680.00$ & $\$ 378,782.40$ & $\$ 448,512.00$ & $\$ 370,723.20$ \\
\hline $\begin{array}{l}\text { Total Annual Fixed Costs } \\
\text { without Taxes } \$ / M W\end{array}$ & $\$ 95,484.00$ & $\$ 136,656.00$ & $\$ 141,912.00$ & $\$ 314,308.80$ & $\$ 406,464.00$ & $\$ 306,249.60$ \\
\hline Total Variable Costs $\$ / M W h$ & $\$ 84.00$ & $\$ 58.00$ & $\$ 53.00$ & $\$ 45.00$ & $\$ 47.00$ & $\$ 24.00$ \\
\hline
\end{tabular}

The levelized costs given in the AESO's report are assumed to be real costs in \$2008. Since our focus is on the real resource cost of producing electricity, we ignore taxes, as these are a transfer to government and do not represent the cost of a resource that has a next best alternative use.

It should be noted that, given the AESO's assumptions, after 2011 the cost of combined cycle gas-fired generation is less than the cost of supercritical pulverized coal generation. This is true for all capacity factors. In other words, beyond 2011, combined cycle gas-fired generation is always less costly on a long-run unit basis than supercritical pulverized coal. As can be seen in the table above, the variable costs of supercritical pulverized coal (before or after 2011) are lower than the variable cost of gas-fired alternatives.

\subsubsection{EVOLUTION OF GENERATION}

\section{New Generation}

Additions of new generation are necessary to meet forecast load growth and to replace generation that has been retired. The amount, type and location of new generation added will impact the forecast power flows on the north-south transmission path and the need for transmission reinforcement. Following the AESO, we assume that market signals will result in capacity equal to peak load plus 10 per cent (i.e., new generation maintains an ERM of 10 per cent) either on a provincewide basis or an area basis, depending on if the north-south transmission constraint is binding. 


\section{Retirements of Existing Generation}

The AESO periodically publishes Long Term Adequacy Metrics ${ }^{56}$ (LTAM) that include a list of generation retirements and retirement dates that have been announced. The latest LTAM indicates the Rossdale 8, 9 and 10 generators in Edmonton and the CT5 and CT8 generators in Medicine Hat will be retired in 2009. All five of these are gas generators. In 2010, the Wabamun 4 coal-fired generator will be retired. In this study we have included the retirements listed in the LTAM in the year they are expected to occur.

In its Long-term Transmission System Plan, the AESO has also provided a list of generators expected to retire by 2017 and by $2027 .^{57}$ However, the year in which each of the generators is expected to retire is not provided. It is anticipated that by 2017, in addition to the units announced in the LTAM, Rainbow 1, 2 and 3 and Sturgeon 1 and 2 simple cycle gas-fired generators will be retired. By 2027 it is expected that Battle River 3, 4, and 5, and Sheerness 1, 2 and the HR Milner coal-fired generators will be retired. It is assumed that the further retirements listed in the Long-term Transmission System Plan will be replaced with generation of similar technology and location.

\section{Wind Generation Additions}

A key requirement for any study of north-south congestion in the Alberta system is the depiction of future wind generation. We have adopted the AESO's expectations for probable wind generation development. ${ }^{58}$ This scenario foresees 6,000 MW of wind generation by $2027 .^{59}$ It is expected that wind generation will be added at approximately $280 \mathrm{MW}$ a year. In this study, all new wind generation is assumed to occur in southern Alberta. The aggregate wind production was modeled to accurately depict historical annual capacity factors as well as regular seasonal variations and fluctuations that occur during each day. New wind generation is aggregated and connected as a single generator at the south $240 \mathrm{kV}$ bus at Janet. This generation is offered at a price that ensures it is always dispatched.

\section{Assumptions of type and location of new generation additions}

Generation that is under construction is modeled according to its type and location. New generation under construction or recently completed includes Cloverbar 2 and 3, CNRL Horizon, MEG Energy and Keephills 3 in the north, and in the south the Crossfield simple cycle gas generator and the Blue Trail wind farm. We did not include projects that have been announced but are not yet under construction such as ENMAX's Bonnybrook and Shepard projects.

\footnotetext{
56 AESO Long Term Adequacy Metrics - May 2009, http://www.aeso.ca/market/17855.html, Accessed Sept. 23, 2009.

57 AESO Long-term Transmission System Plan - Appendix E p. 259, June 2009, http://www.aeso.ca/downloads/AESO_LTTSP_Final_July_2009.pdf, Accessed Sept. 23, 2009.

58 AESO Long-term Transmission System Plan - Appendix G p. 287, June 2009, http://www.aeso.ca/downloads/AESO_LTTSP_Final_July_2009.pdf, Accessed Sept. 23, 2009.

59 This forecast does not include the impact of the Montana Alberta Tieline which will enable wind-energy producers in Montana to sell their output into Alberta. The expected in service date of this line is early 2011. This is an incremental source of energy into southern Alberta that would act to alleviate loading on the Edmonton to Calgary transmission path.
} 
When future wind generation additions are included, further generation additions necessary to maintain an ERM of 10 per cent, even without reinforcement of the transmission grid, can be supercritical pulverized coal generators located in the north. We also consider a scenario where no further wind generation is included. In this case, assuming no transmission reinforcements, generation is added in both the south and north to maintain the AESO's criteria of an ERM of 10 per cent in both areas. Further generation additions necessary to maintain this criterion in the north are assumed to be a combination of supercritical pulverized coal generation and combined cycle gas-fired generation. ${ }^{60}$ Further generation additions necessary to maintain this ERM in the south are assumed to be combined cycle gas generators.

New coal generation is aggregated and connected as a single generator at the north $500 \mathrm{kV}$ bus at Genesee. The offers from new coal generators are assumed to mirror the offers modeled for the existing Genesee 3 generator. ${ }^{61}$ Gas-fired generators that are currently under construction are modelled as separate generators and connected at either the north $500 \mathrm{kV}$ bus at Genesee or the south $240 \mathrm{kV}$ bus at Janet. The offers from new gas generators are assumed to mirror the offers of similar existing generators. The forecast of generation additions and retirements assumed in this study are given in Appendix B.

\subsubsection{GENERIC STACKING ORDER (GSO)}

The dispatch of generation to meet loads affects the magnitude of power flows over various transmission paths. In a deregulated energy-only market such as Alberta, generation is dispatched in order of offer price, with the lowest priced offers being dispatched first. Hence, the offer behaviour of generators affects the final dispatch and the power flows on the transmission paths. To study power flows on a transmission path it is necessary to develop a model of generation dispatch order or the Generic Stacking Order (GSO).

\section{Different Approaches}

In this study we have taken two approaches to model the GSO. The first approach is derived from the GSO created by the AESO as part of their process to determine loss factors. ${ }^{62}$ This dispatch order is based on the historically observed behaviour of generators. Generators in this approach offer their energy in one or more blocks at ascending prices. The strength of this approach is it reflects current dispatch patterns. However, the weakness is that it projects current behaviour into the future, even if conditions change. The second approach is to develop a generation dispatch order based on the estimated variable costs of different generator types. In this approach, generators offer all their capacity in one block. The second approach assumes all generators offer all their capability at their marginal cost of production.

\footnotetext{
60 Some gas-fired generation is required to ensure that the capacity factor of the coal-fired generation remains above 85 per cent.

61 We use Genesee 3 since it is not governed by a power purchase arrangement (PPA) for formerly regulated plants and hence it may be more representative of a new plant than other coal-fired plants whose dispatch rights have been transferred through a PPA.

62 AESO Transmission - Loss Factors - Generic Stacking Order- 2008 Final, August 27, 2007, http://www.aeso.ca/downloads/GSO_2008_20070727_final.pdf, Accessed Sept. 23, 2009.
} 


\section{GSO Hydro and Wind}

Development of an operational GSO required us to make assumptions regarding the treatment of wind and hydro generation.

\section{(i) Wind Generation}

Wind generation occurs when the wind blows and is always dispatched when available: it bids in at a price of zero. In our simulations, a model of wind generation in Alberta was applied that accurately depicts the observed annual capacity factor as well as regular seasonal and diurnal variations in wind generation output. Average hourly outputs are developed based on the installed wind capacity. Hourly outputs in those hours included in the seasonal profiles are averaged to determine the expected wind output for that season and profile.

The output from wind generation is variable. However, the response to this variability is an issue that will need to be addressed whether the north-south transmission is reinforced or not. Currently, the AESO expects that beyond 2018, energy storage will be economical for new wind generation additions. ${ }^{63}$ We assessed the sensitivity of our results to the assumed addition of wind and its expected availability by considering an alternative case where we assumed that there are no further additions of wind capacity in the south.

\section{(ii) Hydro Generation}

Hydro plants on the Bow, Bighorn and Brazeau river systems dominate the hydro system in Alberta, with a combined capacity of approximately $790 \mathrm{MW}^{64}$ The combined output from these plants averages $186 \mathrm{MW}$ in a normal year. However, the output in any one hour can vary from less than $40 \mathrm{MW}$ to over $460 \mathrm{MW}$. These plants have limited storage capability and there are restrictions on how the water flows can be managed. Hydro generation is modelled using standard hourly profiles specifying the MW dispatch for each plant over the course of a year. Like the wind generation, the hourly outputs in the hours included in the seasonal profiles are averaged to determine the expected hydro output for that season and profile. This generation is offered in to the GSO at a price so it is always dispatched. Hydro outputs can vary significantly from year to year based on water inflows throughout the year. To avoid using a GSO that reflected either a wet or dry year, the hydro outputs used are reflective of the long-term average annual hydro production values.

\section{Observed AESO GSO}

The GSO in the first approach is based on historically observed behaviour. It is derived from the GSO used by the AESO for loss factor calculations. To meet the requirements of this study, the AESO's GSO was modified as described below.

63 AESO Long-term Transmission System Plan - Appendix G, June 2009, http://www.aeso.ca/downloads/AESO_LTTSP_Final_July_2009.pdf, Accessed Sept. 23, 2009.

64 AESO Market and System Reporting - Current Supply and Demand, http://ets.aeso.ca/ets_web/ip/Market/Reports/CSDReportServlet, Accessed Sept. 23, 2009. 


\section{(i) Recognition of un-dispatched capacity}

The GSO prepared by the AESO for loss factor calculations reflects the historical output from generators in the province in the previous year. The historical output of each generator is determined by averaging the generator outputs in the hours of the year that correspond to high, medium and low load periods for each of the winter, spring, summer and fall seasons. This results in 12 scenarios or profiles a year. The average output of a generator in any given period is almost always less than its full installed capacity because generator offers may not have been in-merit and/or the unit may have been unavailable due to outages or de-rates. For this study, a block of capacity was added to each generator to recognize the installed capacity that was present but not dispatched. The extra blocks of capacity are added at the end of the GSO so they are only dispatched after all historically dispatched generation has been dispatched.

\section{(ii) Import capacity and position in GSO}

For 2008, the GSO prepared by the AESO for loss factor calculations did not include imports. For this study, we have included the average historical import capability in the hours of the year that correspond to high, medium and low load periods for each of the winter, spring, summer and fall seasons. The historical import capability was obtained from the AESO's website. ${ }^{65}$ Import capability has been positioned in the GSO so that it is dispatched before simple cycle gas generators that are not running under Transmission Must Run (TMR) dispatch orders. Import capacity is dispatched after all wind, hydro, and first energy blocks of cogeneration, coal, and combined cycle plants.

\section{(iii) Available Capacity}

Generators are not always fully available for dispatch because of forced, unplanned and planned outages and occasional de-rates. As an acknowledgement of this, the maximum output of each generator is seasonally reduced to the product of the expected availability and the generator's full capability. The capacities of coal-fired generators are adjusted to reflect an annual availability of 0.9 and the capacities of gas-fired and biomass generators are adjusted to reflect an annual availability of 0.95 . Half of the unavailability of generators is assumed to be due to planned maintenance and half of the unavailability is assumed to be due to forced and unplanned outages and de-rates. It was assumed that no planned maintenance is scheduled during the winter months. The seasonal availability during the non-winter months was adjusted so the annual availability remains as assumed.

The assumed availability by season and generator type is shown in Table 4. However, if historical operation of individual generators indicates higher levels of availability than the assumed levels, the higher levels of availability were adopted.

\section{(iv) Treatment of New Generation Additions}

New wind generation is offered at a price so it is always dispatched in the GSO. The offers from new coal generators are assumed to mirror the offers modelled for the existing Genesee 3 generator. The offers from new gas generators are assumed to mirror the offers of similar existing generators.

65 AESO Market and System Reporting - Interconnection Available Transfer Capacity (ATC) Values, http://itc.aeso.ca/itc/public/atcQueryInit.do, Accessed Sept. 23, 2009. 
TABLE 4

\begin{tabular}{|l|c|c|c|}
\hline \multicolumn{1}{|c|}{ Supplier Type } & $\begin{array}{c}\text { Assumed } \\
\text { Annual }\end{array}$ & $\begin{array}{c}\text { Assumed } \\
\text { Winter Availability }\end{array}$ & $\begin{array}{c}\text { Spring, Summer } \\
\text { and Fall Availability }\end{array}$ \\
\hline Coal Fired Generators & 0.9 & 0.95 & 0.88 \\
\hline Simple Cycle Gas & 0.95 & 0.975 & 0.94 \\
\hline Combined Cycle Gas & 0.95 & 0.975 & 0.94 \\
\hline Co-generation & 0.95 & 0.975 & 0.94 \\
\hline Biomass and Other & 0.95 & 0.975 & 0.94 \\
\hline Wind & 1 & 1 & 1.00 \\
\hline Hydro & 1 & 1 & 1.00 \\
\hline Imports & 1 & 1 & 1.00 \\
\hline
\end{tabular}

\section{Variable Cost Based GSO}

The alternative GSO we use is based on the estimated variable cost of production of each generator type. The estimated variable costs by generator type are provided by the AESO in its Long-term Transmission System Plan (see Table 2 above). ${ }^{66}$ In this approach, all of the available capacity from each generator is offered at the estimated variable cost of production. The GSO is determined by dispatching the generators in order, from the lowest variable cost to the highest variable cost. In cases where two or more generators have the same estimated variable cost, the loss factors for 2008 were used to determine the order of dispatch. New generators are assigned loss factors similar to those of nearby existing generators. The modification to incorporate imports and the treatment of new additions made to the AESO merit order also apply to the variable cost based GSO. New additions are bid in at their estimated variable cost. We also use the annual availability factors in Table 4. For this GSO we do not make an adjustment for observed differences between historical availability and expected availability.

\subsubsection{NORTH-SOUTH TRANSFER LIMITS}

The need for north-south transmission reinforcement is predicated on transmission flows on the north-south path above specified limits. In our models we estimated proxies for these limits by:

(i) Modifying the publicly available system models developed by the $\mathrm{AESO}^{67}$ as part of their transmission loss factor process to reflect the 2008 levels of system loading in each of 12 seasonal profiles.

(ii) Specifying a cut-plane to separate the province into north and south areas.

(iii) Setting imports to zero.

(iv) Specifying the export levels at the historically recorded levels of interconnection Available Transfer Capacity.

66 AESO Long-term Transmission System Plan - Appendix E, p. 255, June 2009, http://www.aeso.ca/downloads/AESO_LTTSP_Final_July_2009.pdf, Accessed Sept. 23, 2009.

67 AESO Transmission - Loss Factors - Base Cases and Raw Data, http://www.aeso.ca/transmission/12921.html, Accessed January 2008. 
(v) Modelling the generation dispatch using the previously discussed modifications to the GSO that the AESO used in developing the transmission loss factors.

The MW flows across the north-south cut plane were then calculated for each of the 12 seasonal loading profiles and these were taken as proxies for the north-south transfer limits in 2008. Twelve transfer limits were calculated: one for each of the four seasons and three load profiles for each season. Table 5 shows the transfer limit proxies that were calculated for each season and load profile. It is observed that these values are very similar to the north-south SOK (south of Keephills - Ellerslie - Genesee) transfer limit levels shown the Edmonton-Calgary $500 \mathrm{kV}$ Transmission Development Need Application. ${ }^{68}$ For those cases where no north-south transmission reinforcement was assumed, the transfer limits were assumed to remain unchanged over the period 2013 to 2028. Because our focus is on the addition of transmission capacity in the Edmonton-Calgary corridor, we use the actual average limits to reflect available capacity. Using actual transfers as a proxy for the transfer limits reflects that transfer capacity is endogenous and depends on the state of Alberta's electric system.

\subsection{Cost Comparison}

The first part of this section provides an estimate of the cost of the two HVDC lines over the period 2013 to 2028. The second part discusses the costs of generation re-dispatch and alternative generation expansion if there is not transmission reinforcement. Unless otherwise noted, our assumptions are the same as those made by the AESO.

TABLE 5

\begin{tabular}{|l|l|c|}
\hline Season & Loading & $\begin{array}{c}\text { Proxy North-South } \\
\text { Transfer Limit (MW) }\end{array}$ \\
\hline Winter & High & 1846.19 \\
\hline Winter & Medium & 1917.47 \\
\hline Winter & Low & 1681.73 \\
\hline Spring & High & 1948.39 \\
\hline Spring & Medium & 2117.02 \\
\hline Spring & Low & 1967.69 \\
\hline Summer & High & 1747.03 \\
\hline Summer & Medium & 1802.84 \\
\hline Summer & Low & 1692.18 \\
\hline Fall & High & 1745.42 \\
\hline Fall & Medium & 1714.33 \\
\hline Fall & Low & 1375.43 \\
\hline
\end{tabular}

${ }^{68}$ Figure 3-3 Page 21 Edmonton-Calgary 500 kV Transmission Development Need Application, May 7, 2004. 


\subsubsection{COST OF NORTH-SOUTH HVDC TRANSMISSION}

The stated cost of the north-south HVDC transmission upgrade is \$3.135 billion (\$2008) and the upgrade is projected to be in service in 2013. ${ }^{69}$ Assuming inflation of 5 per cent a year for the first five years and 2 per cent thereafter, ${ }^{70}$ the nominal capital cost in 2013 is estimated to be $\$ 4.0$ billion.

New capital additions must be operated and maintained. The nominal annual operating and maintenance costs for the new transmission upgrade are assumed to be 1.5 per cent of the initial capital cost, ${ }^{71}$ or $\$ 60$ million per year in 2013 and escalate with inflation thereafter.

The useful life of transmission upgrades is assumed to be 34 years, ${ }^{72}$ but we are interested in the costs over the period from 2013 to 2028 . The NPV (\$2008) of the annual revenue requirements for capital and O\&M costs over this period are determined by first adjusting nominal cost for inflation and then discounting these real costs at a rate of 7 per cent. Using this calculation, the NPV in 2008 is $\$ 2.25$ billion (\$2008). These calculations are detailed in Appendix C.

\subsubsection{COST OF GENERATION RE-DISPATCH AND/OR ALTERNATE GENERATION EXPANSION CASES}

The cost of generation in the unconstrained cases is compared to the constrained cases by modelling the generation dispatch and energy production from each generator in Alberta for each year between 2013 and 2028. The cost of production in the constrained cases is compared to the cost of production assuming unconstrained dispatch.

To compare the costs of unconstrained generation dispatch and constrained dispatch, each of the suppliers in the province was assigned a generation type. The types were: wind, hydro, simple cycle gas, combined cycle gas, co-generation, coal before 2012, coal after 2012, and imports. Biomass and other generation were treated as co-generators. The production from each generator each year was calculated using a generation dispatch order and a system model of high, medium and low load scenarios for each of the winter, spring, summer and fall periods. Generation was dispatched to meet Alberta load and not for export.

The generation from all simple cycle gas, combined cycle gas, co-generation, coal before 2012, coal after 2012, and imports, was summed by type and the variable costs of production were calculated for each year. Existing generation was assumed to have variable costs equal to that of new generation of a similar type in 2008. The cost of production of wind and hydro generation was not calculated because these values did not differ in the compared cases studied in this report.

\footnotetext{
69 AESO Long-term Transmission System Plan - Section 4.3 Edmonton to Calgary transmission system reinforcements, p. 39, June 2009, http://www.aeso.ca/downloads/AESO_LTTSP_Final_July_2009.pdf, Accessed Sept. 23, 2009.

70 AESO Long-term Transmission System Plan - Appendix E, p. 251, June 2009, http://www.aeso.ca/downloads/AESO_LTTSP_Final_July_2009.pdf, Accessed Sept. 23, 2009.

71 Consistent with the AESO's assumptions in the 2004 N-S 500 kV Transmission Needs Application.

72 Consistent with the AESO's assumptions in the 2004 N-S 500 kV Transmission Needs Application.
} 
Existing generation and generation currently under construction are common to all cases. Fixed costs for these do not differ between the cases. The difference in fixed costs between the constrained and unconstrained cases is wholly attributable to differences in the type and amount of new generation added to meet the AESO's expectation of an ERM of 10 per cent either on a provincewide basis or an area basis, depending on if the north-south transmission limits are binding. Because of this, only the fixed costs associated with the type and amount of new generation added to meet the AESO's criteria of an ERM of 10 per cent were calculated.

With the forecast additions of incremental wind generation, the type and amount of installed generation capacity in both the constrained and unconstrained cases is the same. As a result, if wind development occurs as assumed, the fixed costs of the constrained and unconstrained cases will be the same and the increased cost of constrained generation will only be the difference in generation re-dispatch, i.e., variable costs, which are primarily fuel and greenhouse gas offset costs. The extent of wind generation is sufficient that load can be met and north-south transfer limits maintained through re-dispatch of existing generation and committed generation that is currently under construction, without installing incremental gasbased generation in the south. ${ }^{73}$ This is not the case, however, when we assume no further wind development in the south.

The difference in fixed and variable costs between the unconstrained generation and constrained generation case is calculated for each year of the study, and the NPV of the difference to 2008 is calculated using a discount factor of 7 per cent.

Two scenarios are considered. They differ based on whether we use the Observed AESO GSO or the Variable Cost-Based GSO.

The NPV (\$2008) of the cost of generation re-dispatch and/or alternate generation expansion cases for these two scenarios is summarized in Table 6 . The costs presented in Table 6 do not include the avoided cost of the two proposed HVDC transmission lines.

\section{TABLE 6}

\begin{tabular}{|l|c|}
\hline \multicolumn{1}{|c|}{ Scenario } & NPV of Increased Generation Costs in \$2008 \\
\hline Observed AESO GSO & $\$ 228$ million \\
\hline Variable cost based GSO & $\$ 21$ million \\
\hline
\end{tabular}

Forecast increases in southern load are largely met by increased wind generation independent of the two HVDC lines. All new generation (other than new wind generation) added to meet the AESO's ERM expectation can be supercritical pulverized coal in the Edmonton area. Generation re-dispatch is only infrequently required to maintain north-south flows within current limits: 1.7 per cent of total MWhrs for the observed GSO, and 0.2 per cent of the total MWhrs for the variable cost GSO. Assuming generation dispatch is based on the observed AESO GSO, the NPV (\$2008) of the costs of re-dispatching generation to keep north-south flows within current limits is $\$ 228$ million. If the generation dispatch is based on generator variable costs only, the NPV (\$2008) of the costs of re-dispatching generation to keep northsouth flows within current limits is \$21 million.

73 Our base case identifies that the costs of congestion are only a function of re-dispatch. These costs are higher the lower the variable cost of northern generation relative to southern generation. For this reason we assume that additional capacity in the north is coal-fired and not co-generation. See Table 3. 
The net benefit of the two HVDC lines is shown in Table 7. The net benefit is the cost savings from Table 6 less the costs of the two HVDC lines ( $\$ 2.25$ billion). The net benefit is always negative, indicating that the generation-only solution, though not likely optimal, is better. The net benefit is large and negative, primarily because the cost savings from being able to dispatch northern generation instead of southern generation when transmission is unconstrained (i.e., avoiding generation re-dispatch (as shown in Table 6)), are relatively small.

\section{TABLE 7}

\begin{tabular}{|l|c|}
\hline \multicolumn{1}{|c|}{ Scenario } & Net Benefit of HVDC Lines in $\mathbf{\$ 2 0 0 8}$ \\
\hline Observed AESO GSO & $(\$ 2.02$ billion $)$ \\
\hline Variable cost based GSO & $(\$ 2.23$ billion $)$ \\
\hline
\end{tabular}

\subsubsection{SENSITIVITY ANALYSIS}

\section{Gas Price Sensitivity}

The cost of generation re-dispatch is sensitive to the assumed price of natural gas. Lower gas prices make gas generation more attractive, while higher gas prices make coal generation more attractive. Lower gas prices will also lower the cost of generation re-dispatch necessary to maintain north-south within limits. The gas price forecast used by the AESO is shown graphically in Appendix E of the AESO's Long-term Transmission System Plan. ${ }^{74}$ This forecast, which the AESO indicates was obtained in $2008,{ }^{75}$ covers the period between 2008 and 2018 and rarely drops below $\$ 8.00 /$ gigajoule (GJ). After 2018 the gas price was assumed to escalate at 2 per cent per year. The implied real cost of natural gas in \$2008 in the AESO's calculations of LUEC for gas-fired generator types is approximately $\$ 7.46 / \mathrm{GJ}$.

For each of the scenarios investigated, the price of natural gas was increased until the NPV (\$2008) of the generation re-dispatch was equal to the NPV in 2013 of the proposed northsouth HVDC transmission upgrade. The gas prices where the costs of re-dispatch match the cost of the proposed north-south HVDC transmission upgrade are summarized in the Table 8. The impact of the gas price on the difference in cost between cases is minimal. The northsouth transfer limits can be met through minimal redispatch and without the addition of new gas-based generators in the Calgary region. As a result, the increase in the gas price required to make the two HVDC lines the minimal cost is very large. ${ }^{76}$

\section{TABLE 8}

\begin{tabular}{|l|c|}
\hline \multicolumn{1}{|c|}{ Scenario } & $\begin{array}{r}\text { Gas Price in \$2008/GJ so NPV of cost of Generation Re-dispatch equals } \\
\text { NPV of planned north-south HVDC transmission upgrade }\end{array}$ \\
\hline Observed AESO GSO & $\$ 66.80 / \mathrm{GJ}$ \\
\hline Variable cost based GSO & $\$ 790.70 / \mathrm{GJ}$ \\
\hline
\end{tabular}

\footnotetext{
74 AESO Long-term Transmission System Plan - Appendix E, p. 252, June 2009, http://www.aeso.ca/downloads/AESO_LTTSP_Final_July_2009.pdf, Accessed Sept. 23, 2009.

75 AESO Long-term Transmission System Plan - Appendix E, p. 252, June 2009, http://www.aeso.ca/downloads/AESO_LTTSP_Final_July_2009.pdf, Accessed Sept. 23, 2009.

76 The $\$ 790.70$ price is not a typo.
} 


\section{Greenhouse Gas Offset Cost Sensitivity}

The cost of generation re-dispatch is sensitive to the assumed cost of GHG offsets. Lower GHG offset costs make coal generation more attractive, and higher GHG offset costs make gas generation more attractive. For the two generic stacking orders GHG offset costs were reduced to zero. The NPV (\$2008) of the cost of the generation re-dispatch and alternative expansion necessary to keep north-south flows within limits is summarized in Table 9. The costs presented in Table 9 do not include the avoided cost of the two proposed HVDC transmission lines.

A comparison of the NPV of increased costs shown in Table 6 and Table 9 indicates that assuming GHG cost offsets are eliminated will not significantly alter the NPV of increased costs of generator re-dispatch to maintain north-south transfers within limits.

TABLE 9

\begin{tabular}{|l|c|}
\hline \multicolumn{1}{|c|}{ Scenario } & $\begin{array}{r}\text { NPV of Generation Re-dispatch (\$2008) assuming GHG } \\
\text { offset costs are reduced to zero }\end{array}$ \\
\hline Observed AESO GSO & $\$ 245$ million \\
\hline Variable cost based GSO & $\$ 23$ million \\
\hline
\end{tabular}

\section{Line Losses}

The impact on transmission losses of generation re-dispatch compared to the proposed northsouth HVDC transmission reinforcement and unconstrained dispatch was not evaluated. However, the proposed HVDC transmission upgrade will reduce but not eliminate system losses. Generation re-dispatch to maintain north-south flow limits will tend to maintain losses at current levels. Line losses for the entire transmission system were \$236 million in 2008 and are forecast to be $\$ 126.2$ million in 2009. ${ }^{77}$ The average (expected) line losses per year over 2008 and 2009 for the AIES are approximately \$180 million. If north-south reinforcement eliminated 25 per cent of these losses, then an additional cost of not introducing the two HVDC lines (and no other reinforcement alternative) from continued lines losses would have a NPV of \$292 million (\$2008). Table 10 shows the NPV of the net benefit of the two HVDC lines when line losses are incorporated into our results. The net benefit is the sum of generation cost savings plus line loss reduction less the cost of the two HVDC lines.

TABLE 10

\begin{tabular}{|l|c|c|c|c|}
\hline \multicolumn{1}{|c|}{ Scenario } & $\begin{array}{c}\text { Generation } \\
\text { Cost Savings }\end{array}$ & $\begin{array}{c}\text { Line Loss } \\
\text { Reduction }\end{array}$ & $\begin{array}{c}\text { Cost of HVDC } \\
\text { Lines }\end{array}$ & $\begin{array}{c}\text { Net Benefit of } \\
\text { HVDC Lines (\$2008) } \\
\text { relative to } \\
\text { Generation only }\end{array}$ \\
\hline Observed AESO GSO & $\$ 228$ million & $\$ 292$ million & $\$ 2.25$ billion & $(\$ 1.73$ billion) \\
\hline Variable cost based GSO & $\$ 21$ million & $\$ 292$ million & $\$ 2.25$ billion & $(\$ 1.94$ billion $)$ \\
\hline
\end{tabular}

77 AESO Transmission - Loss Factors - Calibration Factors-2009, http://www.aeso.ca/downloads/Q3_2009_Rider_E_Estimate.pdf, Accessed Sept. 23, 2009. 
Even if all line losses were eliminated if the two HVDC lines were added, raising the benefit of the reduction in line losses by another $\$ 880$ million, the net benefit of the two HVDC lines would still be between ( $\$ 852$ million) and ( $\$ 1.06$ billion).

\section{Wind}

We also explore the sensitivity of our results to the assumption that wind power in southern Alberta will develop as expected by the AESO. The assumption in the planning scenarios (made by the AESO and us) is to de-rate wind based on its average availability. For instance, the estimated 6,000 MW of wind expected by 2028 produces an average of 2,120 MW of output. ${ }^{78}$ The problem is that this average will not be representative of the variation in energy production in any given hour. To the extent that wind generation from various facilities is positively correlated, then the average could be misleading. If the correlation is one, then situations can arise where either all of the wind is available or none of it is available. In their long-term plan, the AESO assume that wind is "firmed" after 2018. ${ }^{79}$ Firming means that the average de-rated capacity will always be available even if the wind does not blow.

The alternatives for firming include investment in additional capacity equal to the de-rated expected capacity. In the constrained case this would likely be gas-fired generation in the south. In the unconstrained case this could be some combination of coal or gas in the north or gas in the south. Of course there are other alternatives to achieve firming of the wind capacity, including storage, or expanding the capabilities of the tie line with British Columbia.

Given the AESO's assumptions regarding greenhouse gas offset costs, gas-fired generation in the south has lower long-run unit costs and does not require investment in transmission. Hence, gas-fired generation in the south is preferred; location signals should ensure such an outcome. This conclusion holds even if greenhouse gas offset costs are reduced by up to 40 per cent.

On the other hand, if greenhouse gas offset costs fall by more than 40 per cent, then the longrun unit costs of coal can be lower than gas-fired generation at sufficiently high-capacity factors. For instance, if greenhouse gas offset costs are zero, then coal-fired generation has a lower long-run unit cost than gas if the capacity factor is greater than 60 per cent. For greenhouse gas offset costs less than 60 per cent of the AESO's assumed value, it may be possible that expanding coal generation in the north and adding transmission capacity would be less costly to firm up wind than gas in the south.

Using coal-fired generation to firm up wind capacity is not likely to be optimal because coalfired generation is typically baseloaded. It would be more natural to assume that the choice is between gas-fired capacity in the south and gas-fired capacity in the north plus transmission. In that case, the best choice is gas-fired generation in the south since the generation cost is the same and an expansion of transmission capacity is not required. An alternative interpretation that makes coal-fired generation in the north a more logical alternative, and which is consistent with our modeling, is that wind generation is simply not developed. This is an extreme assumption that favours the development of coal in the north and adding transmission capacity.

78 AESO Long-term Transmission System Plan - Appendix G, June 2009. The AESO assumes a range of capacity availability for wind, from 27.5 per cent to 37.5 per cent, with an average value of 32.5 per cent. Based on historical wind dispatch, we assume instead a 35 per cent capacity availability.

79 AESO Long-term Transmission System Plan - Appendix G, June 2009 at p. 284: With respect to wind power, "It was assumed that an economic energy storage technology would be available to projects built in 2018 and after." 
We consider whether our conclusion regarding the economic efficiency of the proposed HVDC lines is robust to zero greenhouse gas offset costs and no additional wind investment after 2009, assuming variable cost based dispatch. In the unconstrained case, we assume that coal and gas-fired capacity is added in the north, where we limit the amount of incremental coal generation added so that it operates at a capacity factor of 85 per cent or more. In the constrained case, incremental generation in the north is coal and gas, where we again limit the amount of incremental coal generation added so that it operates at a capacity factor of 85 per cent or more and only gas-fired generation in the south. Under these assumptions we find that the net present value of the lower generation costs in the unconstrained case is $\$ 815$ million (\$2008) instead of \$21 million (\$2008). Though a large increase in the benefit associated with the two HVDC lines, the net present value of the cost of the two HVDC lines is still $\$ 1.1$ billion more than the generation-only solution, and it assumes the cost of greenhouse gas offset costs are zero. (See Table 11.)

TABLE 11

\begin{tabular}{|c|c|c|c|c|}
\hline Scenario & $\begin{array}{c}\text { Generation } \\
\text { Cost Savings }\end{array}$ & $\begin{array}{c}\text { Line Loss } \\
\text { Reduction }\end{array}$ & $\begin{array}{c}\text { Cost of HVDC } \\
\text { Lines }\end{array}$ & $\begin{array}{c}\text { Net Benefit of HVDC } \\
\mathbf{( \$ 2 0 0 8 )} \text { relative } \\
\text { to Generation only }\end{array}$ \\
\hline Variable cost based GSO & $\$ 815$ million & $\$ 292$ million & $\$ 2.25$ billion & $(\$ 1.14$ billion $)$ \\
\hline
\end{tabular}

\subsubsection{OBSERVATIONS}

In this part we make a number of observations regarding our methodology and the conclusions.

\section{Load Forecast}

The AESO's forecast load growth (in both its 2007 and 2008 forecasts) is high compared to recent history. If load growth continues at the levels seen over the past three years, the growth in north-south flows will be abated. In this case, the frequency and duration of periods when generation re-dispatch is needed in the absence of transmission reinforcements to limit flows on the north-south path will be less and the net benefit of NPV of the HVDC lines will become even more negative.

\section{Real Option Analysis}

In our analysis, we explored the sensitivity of our results to some key assumptions. Explicitly incorporating uncertainty about key variables into the analysis is important, but beyond our scope here. Instead, it is worthwhile to understand that a real option analysis would indicate that in situations of uncertainty regarding greenhouse gas offset costs, the price of gas, and load growth, there is an additional cost associated with the two HVDC lines relative to the combined cycle gas generation solution. The additional cost arises because choosing the two HVDC lines is riskier. The investment required for the two HVDC lines is large and sunk. Hence, a decision to expand transmission runs the risk of having some capacity stranded, or underutilized for extended periods of time if load growth is smaller than expected, gas prices remain low and greenhouse gas offset costs are high. The real option perspective is that there is an additional cost to investing early in sunk capital assets before uncertainty is, at least 
partially, resolved. By waiting, more information becomes available, allowing for better decision making. The advantage of gas generation is that it is scalable and much more flexible. Gas generation can be constructed in a shorter time period than transmission, it is possible to slow the installation of total capacity if warranted by changes in the economic environment, and building gas generation does not preclude making large investments in transmission in the future.

\section{Other Benefits of Transmission Expansion}

Other benefits associated with transmission expansion have been suggested. The three most prominent are mitigation of market power, reliability, and preservation of the single price, energy only market.

The market power concern is that reinforcement of the north-south transmission path is necessary to avoid the exercise of market power in southern Alberta. This is a possibility, though it is not obvious, given the anticipated extent of wind generation and measures that will result in its firming. Over the period of our simulations, 2013 to 2028, in the wind-as-expected case, the Herfindahl-Hirschman Index (HHI) (based on capacity shares) that excludes northsouth transfers never exceeds $1,348 .^{80}$ An HHI of 1,348 is not likely indicative of a market power problem. $^{81}$

In any event, there are two relevant questions. First, is the cost of market power greater than $\$ 1.7$ to $\$ 1.9$ billion? The benefit from disciplining market power by installing the two HVDC lines must exceed its cost for market power considerations to justify the two HVDC lines. However, it is not sufficient to conclude that the two HVDC lines are economic because they control market power. The second question that needs to be asked is whether there are cheaper alternatives to mitigate the development of market power in southern Alberta. If there are, then the two HVDC lines remain uneconomic.

A suggested benefit of the two HVDC lines is that they are necessary to meet reliability requirements. It is important to distinguish between the costs of congestion and the costs of unreliability. Our analysis measures the cost of congestion. In doing so, we continue to meet current reliability requirements. In its Long-term Transmission System Plan 2009, the AESO projects that by 2014 reliability criteria will be violated without transmission reinforcement. ${ }^{82}$ In our simulations, the transfer limits without the two HVDC lines are based on the 2008 observed limits, so even in the constrained case, the reliability requirements continue to be met assuming the expected wind capacity is available. We address that wind might not be available by considering an alternative case where wind capacity is replaced by gas-fired generation in southern Alberta. In this case, the current reliability requirements continue to be met.

80 The Herfindahl-Hirschman Index (HHI) is an index of market power. It equals the sum of squared market shares. It ranges from 0 (perfect competition) to 10,000 (monopoly).

${ }^{81}$ We admit that the application of HHI to electricity markets may be problematic. However, it shares many of the same difficulties associated with diagnosing market power based on market share, the measure used in the Fair, Efficient and Open Competition Regulation (Alberta Regulation 159/2009). Section 5(5) of the Fair, Efficient and Open Competition Regulation limits the market share (based on capacity) of a market participant to 30 per cent.

82 AESO Long-term Transmission System Plan - Section 4.3 Edmonton to Calgary transmission system reinforcements. Subsection 4.3.3 Alignment with planning objectives. 
A third objection to our analysis does not address the costs and benefits of the two HVDC lines as such, but instead is that, moving away from the zero congestion policy and towards location based price signals that reflect congestion costs and costs of service would jeopardize the market design in Alberta. In particular, a leap appears to be made that the only way to implement location-based charges is to introduce locational marginal pricing (LMP) or nodal pricing for energy. Under LMP, a price is set at every node in the electric network and differences in prices reflect transmission costs. However, it is not necessary to have locational signals in the energy market. Instead it is possible to have locational signals embedded in the price of transmission access. It may be possible, for instance, to institute locational access prices for transmission without requiring extensive changes in the market design.$^{83}$

There may be other benefits that we have not considered that justify the two HVDC lines. However, to overturn our conclusion that the two HVDC lines are inefficient, it is necessary to establish that any such advantages outweigh the $\$ 1.7$ billion to $\$ 1.9$ billion of additional cost from the transmission line construction. It must also be proven that any other benefits cannot be achieved by a less expensive alternative.

83 On the Nova gas pipeline system in Alberta receipt charges are differentiated by location and cost. 


\subsection{USING INDEPENDENT REGULATORS: THE COSTS AND BENEFITS OF DELEGATION}

Bill 50 raises an interesting question involving the regulatory approval process for electrical transmission lines: does it warrant suspension of the needs assessment? There are a number of advantages associated with using an independent regulator to assess whether a transmission project is in the public interest. These advantages include the following:

(a) It is easier for an independent regulator to commit to regulatory policy, therefore reducing political and regulatory risk and encouraging investment.

(b) It is less likely that project approval and conditions will be driven by short-term political interests, and more likely that a focus on long-run benefits and costs can be maintained.

(c) Regulatory agencies typically have relevant expertise, historic awareness and background knowledge to understand, evaluate and adjudicate complex issues.

(d) Regulatory processes are designed to subject interested parties' positions to public scrutiny and evaluation. They provide a forum for a public debate and record that reduces the issues and problems caused by asymmetric information and strategic behaviour.

(e) Regulatory processes guard against private interests having an undue influence.

(f) Public regulatory processes make explicit the alternatives available and require the regulator, through written decisions, to explain their rationale. This is an important constraint on any potential collusion between the decision maker and private interests.

(g) Regulatory processes allow for public participation and monitoring, contributing to accountability, understanding and legitimacy.

The disadvantages of a regulatory process with regard to approval of a transmission project are the costs of approvals may be higher, and that decisions may not be timely. Unilateral action by a government is likely to be superior only if there is widespread agreement that a problem exists, time is of the essence, and the cost of not addressing the problem dwarfs the cost of not exploring alternatives. These conditions imply that some response is more important than determining which response, if any, is optimal. It is important to distinguish between the general concept of critical infrastructure, and the four projects identified as critical in Bill 50. It is not clear that the critical infrastructure identified in Bill 50 meets all of these requirements. In general, it is not expected that a transmission project would meet these conditions.

Our results show that the two proposed HVDC lines are economically inefficient and unwarranted given the AESO's assumptions and forecasts, while maintaining the same supply adequacy and reliability requirements. Such findings are indicative of the benefit of a regulatory process and raise doubts that there is an emergency. 
Any benefits of the regulatory process depend on how well it functions. The two-stage needs identification process leaves a lot to be desired, as suggested by the difficulties with landowners that resulted in the 2005 approval of the needs application for two $500 \mathrm{kV} \mathrm{AC}$ transmission lines between Edmonton and Calgary being voided in 2007. ${ }^{84}$ Difficulties associated with the legislative framework and/or irregular conduct by the regulator in the past should not be deemed evidence that regulation does not work, nor does it justify an emergency response. If the existing regulatory process is found to be dysfunctional (and there appears to be frustration on the part of generators at the pace of transmission expansion), the answer is likely that it is better to institute regulatory reform than abandon regulation. The uproar over Bill 50 and the two HVDC lines shows the value of a regulatory process. The debate over transmission investment and additions should not be in the media and between duelling websites. Albertans deserve better.

84 The decision was voided in 2007 after it was learned the Alberta Energy and Utilities Board had hired private investigators to observe landowners who had intervened in the regulatory process. In response, the Province split the Board into two regulatory bodies as of Jan. 1, 2008: the Alberta Utilities Commission and the Energy Resources Conservation Board. The utilities commission oversees distribution and sale of electricity and natural gas to consumers, as well as handling applications for new or upgraded transmission lines. The conservation board focuses on development of Alberta's oil and gas reserves. 


\section{APPENDIX A: FORECAST AIES LOAD: ANNUAL ENERGY AND PEAK DEMAND}

Forecast AIES Load (Based On AESO FC 2007)

\begin{tabular}{|c|c|c|c|c|}
\hline Year & Energy (GWh) & Growth & Peak Demand (MW) & Growth \\
\hline 2009 & 60422 & - & 9148 & - \\
\hline 2010 & 62062 & $2.7 \%$ & 9456 & $3.4 \%$ \\
\hline 2011 & 63951 & $3.0 \%$ & 9750 & $3.1 \%$ \\
\hline 2012 & 66379 & $3.8 \%$ & 10064 & $3.2 \%$ \\
\hline 2013 & 68790 & $3.6 \%$ & 10425 & $3.6 \%$ \\
\hline 2014 & 70854 & $3.0 \%$ & 10719 & $2.8 \%$ \\
\hline 2015 & 73094 & $3.2 \%$ & 11005 & $2.7 \%$ \\
\hline 2016 & 75550 & $3.4 \%$ & 11328 & $2.9 \%$ \\
\hline 2017 & 77582 & $2.7 \%$ & 11647 & $2.8 \%$ \\
\hline 2018 & 79328 & $2.3 \%$ & 11909 & $2.2 \%$ \\
\hline 2019 & 81248 & $2.4 \%$ & 12188 & $2.3 \%$ \\
\hline 2020 & 83957 & $3.3 \%$ & 12560 & $3.1 \%$ \\
\hline 2021 & 86496 & $3.0 \%$ & 13000 & $3.5 \%$ \\
\hline 2022 & 89068 & $3.0 \%$ & 13422 & $3.2 \%$ \\
\hline 2023 & 91700 & $3.0 \%$ & 13856 & $3.2 \%$ \\
\hline 2024 & 94405 & $2.9 \%$ & 14250 & $2.8 \%$ \\
\hline 2025 & 97226 & $3.0 \%$ & 14758 & $3.6 \%$ \\
\hline 2026 & 100065 & $2.9 \%$ & 15223 & $3.2 \%$ \\
\hline 2027 & 103014 & $2.9 \%$ & 15703 & 16198 \\
\hline 2028 & 106049 & $2.9 \%$ & & \\
\hline
\end{tabular}




\section{APPENDIX B: FORECAST GENERATION ADDITIONS AND RETIREMENTS}

Generation Additions - With Wind Power Additions

\begin{tabular}{|c|c|c|c|c|c|}
\hline Year & $\begin{array}{c}\text { North } \\
\text { Coal } \\
\text { (MW) }\end{array}$ & $\begin{array}{c}\text { North } \\
\text { Simple Cycle } \\
\text { (MW) }\end{array}$ & $\begin{array}{c}\text { North } \\
\text { Co-Generation } \\
\text { (MW) }\end{array}$ & $\begin{array}{c}\text { South } \\
\text { Wind } \\
\text { (MW) }\end{array}$ & $\begin{array}{c}\text { South } \\
\text { Simple Cycle } \\
\text { Gas (MW) }\end{array}$ \\
\hline 2009 & 0 & 101 & 188 & 280 & 0 \\
\hline 2010 & 0 & 101 & 0 & 230 & 120 \\
\hline 2011 & 450 & 0 & 0 & 280 & 0 \\
\hline 2012 & 86 & 0 & 0 & 280 & 0 \\
\hline 2013 & 514 & 0 & 0 & 280 & 0 \\
\hline 2014 & 624 & 0 & 0 & 280 & 0 \\
\hline 2015 & 536 & 0 & 0 & 280 & 0 \\
\hline 2016 & 497 & 0 & 0 & 280 & 0 \\
\hline 2017 & 490 & 0 & 0 & 280 & 0 \\
\hline 2018 & 373 & 0 & 0 & 280 & 0 \\
\hline 2019 & 349 & 0 & 0 & 280 & 0 \\
\hline 2020 & 446 & 0 & 0 & 280 & 0 \\
\hline 2021 & 444 & 0 & 0 & 280 & 0 \\
\hline 2022 & 398 & 0 & 0 & 280 & 0 \\
\hline 2023 & 431 & 0 & 0 & 280 & 0 \\
\hline 2024 & 415 & 0 & 0 & 280 & 0 \\
\hline 2025 & 440 & 0 & 0 & 280 & 280 \\
\hline 2026 & 477 & 0 & 0 & 280 & 0 \\
\hline 2027 & 492 & 0 & 0 & 0 & 0 \\
\hline 2028 & 474 & 0 & 0 & 0 \\
\hline
\end{tabular}


Generation Additions - No Additional Wind Power and without N-S Trans Reinforcement

\begin{tabular}{|c|c|c|c|c|c|c|c|}
\hline Year & $\begin{array}{l}\text { North } \\
\text { Coal } \\
(\mathrm{MW})\end{array}$ & $\begin{array}{c}\text { North } \\
\text { Combined Cycle } \\
\text { (MW) }\end{array}$ & $\begin{array}{c}\text { North } \\
\text { Co-Generation } \\
\text { (MW) }\end{array}$ & $\begin{array}{c}\text { North } \\
\text { Simple } \\
\text { Cycle Gas (MW) }\end{array}$ & $\begin{array}{l}\text { South } \\
\text { Wind } \\
\text { (MW) }\end{array}$ & $\begin{array}{c}\text { South } \\
\text { Simple Cycle } \\
\text { Gas (MW) }\end{array}$ & $\begin{array}{c}\text { South } \\
\text { Combined } \\
\text { Cycle (MW) }\end{array}$ \\
\hline 2009 & 0 & 0 & 188 & 101 & 66 & 0 & 795 \\
\hline 2010 & 0 & 0 & 0 & 101 & 0 & 120 & 45 \\
\hline 2011 & 450 & 0 & 0 & 0 & 0 & 0 & 313 \\
\hline 2012 & 0 & 0 & 0 & 0 & 0 & 0 & 233 \\
\hline 2013 & 0 & 0 & 0 & 0 & 0 & 0 & 278 \\
\hline 2014 & 0 & 251 & 0 & 0 & 0 & 0 & 242 \\
\hline 2015 & 86 & 241 & 0 & 0 & 0 & 0 & 226 \\
\hline 2016 & 153 & 170 & 0 & 0 & 0 & 0 & 223 \\
\hline 2017 & 117 & 136 & 0 & 0 & 0 & 0 & 175 \\
\hline 2018 & 105 & 134 & 0 & 0 & 0 & 0 & 165 \\
\hline 2019 & 121 & 176 & 0 & 0 & 0 & 0 & 205 \\
\hline 2020 & 144 & 151 & 0 & 0 & 0 & 0 & 204 \\
\hline 2021 & 236 & 33 & 0 & 0 & 0 & 0 & 186 \\
\hline 2022 & 288 & 0 & 0 & 0 & 0 & 0 & 199 \\
\hline 2023 & 278 & 0 & 0 & 0 & 0 & 0 & 192 \\
\hline 2024 & 293 & 0 & 0 & 0 & 0 & 0 & 203 \\
\hline 2025 & 315 & 0 & 0 & 0 & 0 & 0 & 218 \\
\hline 2026 & 324 & 0 & 0 & 0 & 0 & 0 & 224 \\
\hline 2027 & 313 & 0 & 0 & 0 & 0 & 0 & 216 \\
\hline 2028 & 318 & 0 & 0 & 0 & 0 & 0 & 220 \\
\hline
\end{tabular}


Generation Additions - No Additional Wind Power and with N-S Trans Reinforcement

\begin{tabular}{|c|c|c|c|c|c|c|}
\hline Year & $\begin{array}{l}\text { North } \\
\text { Coal } \\
\text { (MW) }\end{array}$ & $\begin{array}{c}\text { North } \\
\text { Combined Cycle } \\
\text { (MW) }\end{array}$ & $\begin{array}{c}\text { North } \\
\text { Co-Generation } \\
\text { (MW) }\end{array}$ & $\begin{array}{c}\text { North } \\
\text { Simple } \\
\text { Cycle Gas (MW) }\end{array}$ & $\begin{array}{l}\text { South } \\
\text { Wind } \\
\text { (MW) }\end{array}$ & $\begin{array}{c}\text { South } \\
\text { Simple Cycle } \\
\text { Gas (MW) }\end{array}$ \\
\hline 2009 & 0 & 0 & 188 & 101 & 66 & 0 \\
\hline 2010 & 0 & 0 & 0 & 101 & 0 & 120 \\
\hline 2011 & 931 & 283 & 0 & 0 & 0 & 0 \\
\hline 2012 & 0 & 0 & 0 & 0 & 0 & 0 \\
\hline 2013 & 227 & 574 & 0 & 0 & 0 & 0 \\
\hline 2014 & 251 & 341 & 0 & 0 & 0 & 0 \\
\hline 2015 & 239 & 314 & 0 & 0 & 0 & 0 \\
\hline 2016 & 243 & 304 & 0 & 0 & 0 & 0 \\
\hline 2017 & 188 & 241 & 0 & 0 & 0 & 0 \\
\hline 2018 & 166 & 239 & 0 & 0 & 0 & 0 \\
\hline 2019 & 188 & 314 & 0 & 0 & 0 & 0 \\
\hline 2020 & 245 & 255 & 0 & 0 & 0 & 0 \\
\hline 2021 & 454 & 0 & 0 & 0 & 0 & 0 \\
\hline 2022 & 487 & 0 & 0 & 0 & 0 & 0 \\
\hline 2023 & 471 & 0 & 0 & 0 & 0 & 0 \\
\hline 2024 & 282 & 214 & 0 & 0 & 0 & 0 \\
\hline 2025 & 264 & 269 & 0 & 0 & 0 & 0 \\
\hline 2026 & 272 & 276 & 0 & 0 & 0 & 0 \\
\hline 2027 & 276 & 254 & 0 & 0 & 0 & 0 \\
\hline 2028 & 282 & 256 & 0 & 0 & 0 & 0 \\
\hline
\end{tabular}


Generator Additions to 2008 Case (Under Construction or Recently Completed)

\begin{tabular}{|l|c|c|c|c|}
\hline \multicolumn{1}{|c|}{ Generator/Year Available } & $\mathbf{2 0 0 9}$ & $\mathbf{2 0 1 0}$ & $\mathbf{2 0 1 1}$ & North or South \\
\hline Blue Trail Wind & $66 \mathrm{MW}$ & - & - & South \\
\hline Cloverbar 2 Gas Fired & $101 \mathrm{MW}$ & - & - & North \\
\hline CNRL Horizon Cogeneration & $103 \mathrm{MW}$ & - & - & North \\
\hline MEG Energy Cogeneration & $85 \mathrm{MW}$ & - & - & North \\
\hline Cloverbar 3 Gas Fired & - & $101 \mathrm{MW}$ & - & North \\
\hline Crossfield Gas Fired & - & $120 \mathrm{MW}$ & - & South \\
\hline Keephills 3 Coal Fired & - & - & $450 \mathrm{MW}$ & North \\
\hline
\end{tabular}

Note: All Generation Additions are modeled as available beginning in the first quarter following the expected commissioning date

Generation Retirements

\begin{tabular}{|l|c|c|c|}
\hline \multicolumn{1}{|c|}{ Generator/Year Available } & $\mathbf{2 0 0 9}$ & $\mathbf{2 0 1 0}$ & North or South \\
\hline Rossdale 8,9,10 Gas Fired & $209 \mathrm{MW}$ & - & North \\
\hline Medicine Hat Gas Generation & $37 \mathrm{MW}$ & - & South \\
\hline Wabamun 4 Coal Fired Generation & - & $279 \mathrm{MW}$ & North \\
\hline
\end{tabular}

Note: All Generation Retirements are modeled as out of service beginning in the first quarter following the expected retirement date 


\section{APPENDIX C: NPV (\$2008) OF PROPOSED N-S HVDC TRANSMISSION ADDITION}

\begin{tabular}{|c|c|c|}
\hline के & 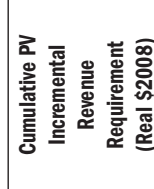 & 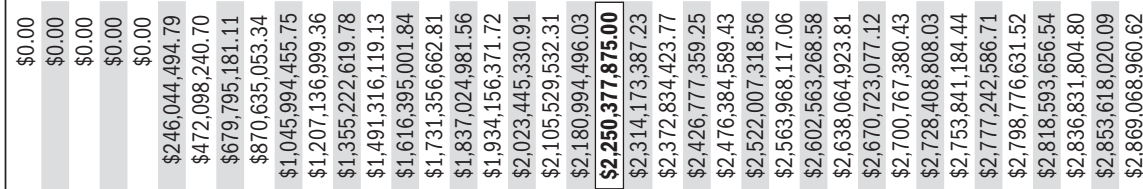 \\
\hline \multirow{3}{*}{ 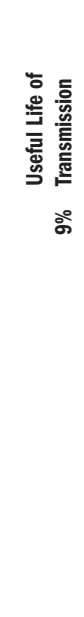 } & 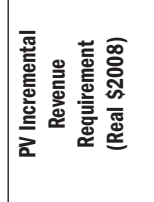 & 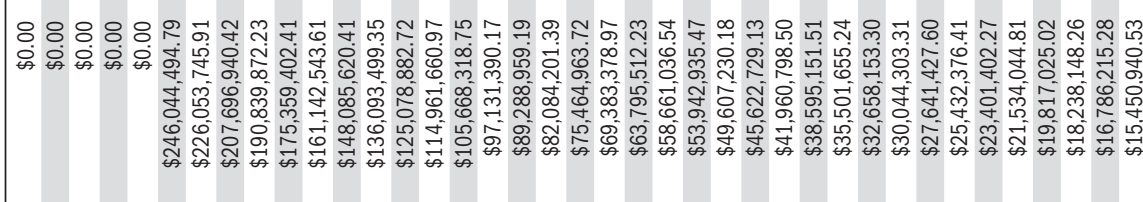 \\
\hline & 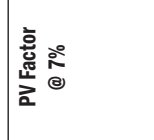 & 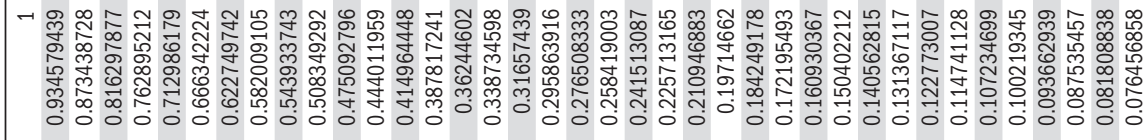 \\
\hline & 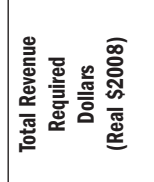 & 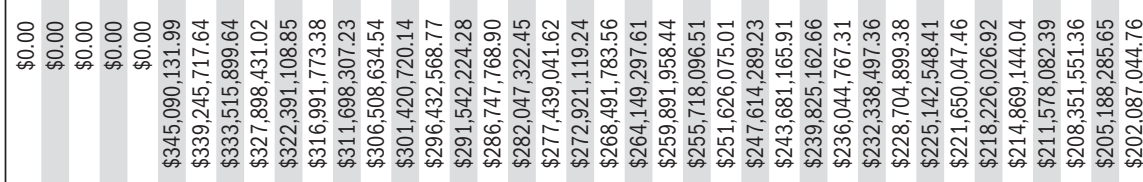 \\
\hline \multirow[t]{2}{*}{$\stackrel{\circlearrowright}{3}$} & 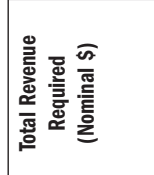 & 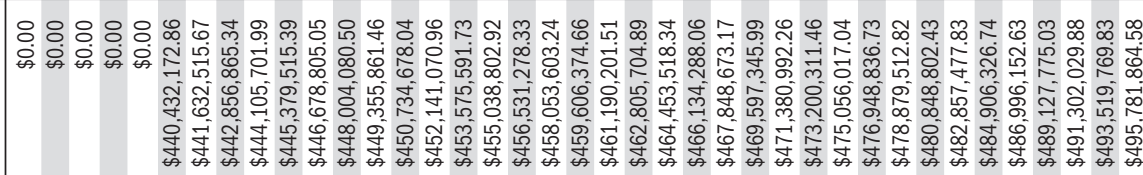 \\
\hline & 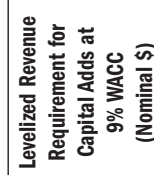 & 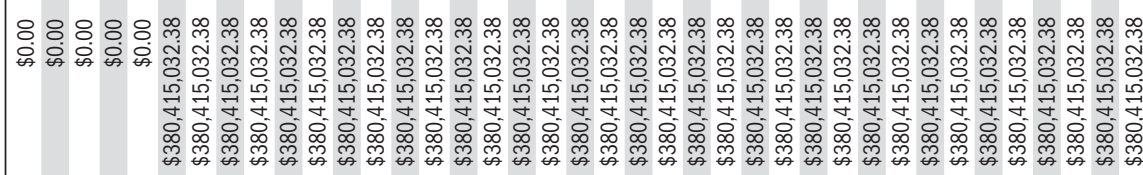 \\
\hline ओं & 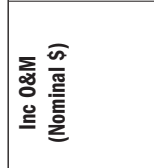 & 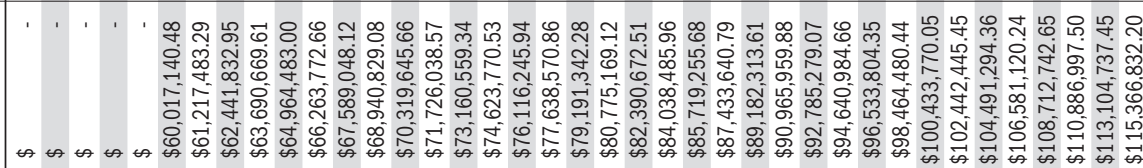 \\
\hline 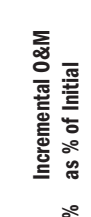 & 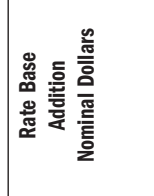 & 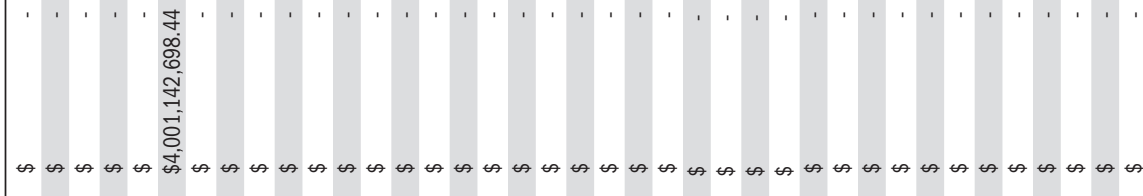 \\
\hline & 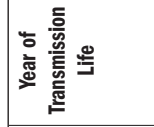 & m \\
\hline & 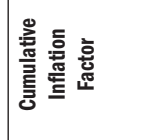 & 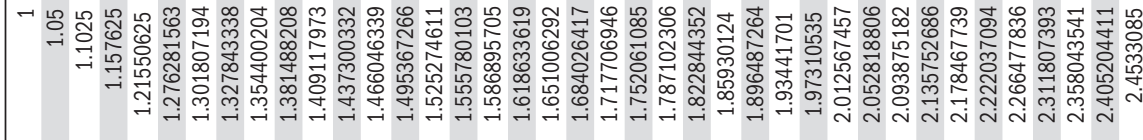 \\
\hline & 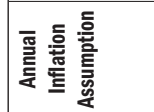 & 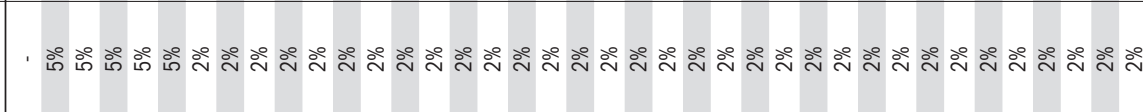 \\
\hline $\begin{array}{l}\text { 言 } \\
\text { 誊 흠 }\end{array}$ & 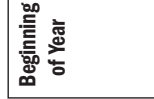 & 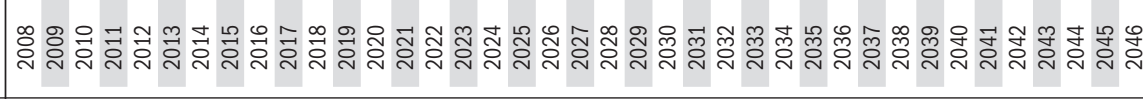 \\
\hline
\end{tabular}




\section{ABOUT THIS PUBLICATION}

SPP Research Papers are published by The School of Public Policy at the University of Calgary to provide timely, in-depth studies of current issues in public policy.

\section{OUR MANDATE}

The University of Calgary is home to scholars in 16 faculties (offering more than 80 academic programs) and 36 Research Institutes and Centres including The School of Public Policy. Under the direction of Jack Mintz, Palmer Chair in Public Policy, and supported by more than 100 academics and researchers, the work of The School of Public Policy and its students contributes to a more meaningful and informed public debate on fiscal, social, energy, environmental and international issues to improve Canada's and Alberta's economic and social performance.

The School of Public Policy achieves its objectives through fostering ongoing partnerships with federal, provincial, state and municipal governments, industry associations, NGOs, and leading academic institutions internationally. Foreign Investment Advisory Committee of the World Bank, International Monetary Fund, Finance Canada, Department of Foreign Affairs and International Trade Canada, and Government of Alberta, are just some of the partners already engaged with the School's activities.

For those in government, The School of Public Policy helps to build capacity and assists in the training of public servants through degree and non-degree programs that are critical for an effective public service in Canada. For those outside of the public sector, its programs enhance the effectiveness of public policy, providing a better understanding of the objectives and limitations faced by governments in the application of legislation.

\section{DISTRIBUTION}

Our publications are available online at www.policyschool.ca.

\section{DISCLAIMER}

The opinions expressed in these publications are the authors' alone and therefore do not necessarily reflect the opinions of the supporters, staff, or boards of The School of Public Policy.

\section{COPYRIGHT}

Copyright ( 2009 by The School of Public Policy.

All rights reserved. No part of this publication may be reproduced in any manner whatsoever without written permission except in the case of brief passages quoted in critical articles and reviews.

\section{ISSN}

1919-112x SPP Research Papers (Print) 1919-1138 SPP Research Papers (Online)

\section{DATE OF ISSUE}

November 2009

\section{MEDIA INQUIRIES AND INFORMATION}

For media inquiries, please contact Morten Paulsen at 403-453-0062.

Our web site, www.policyschool.ca, contains more information about The School's events, publications, and staff.

\section{DEVELOPMENT}

For information about becoming a supporter of The School of Public Policy, please contact Cheryl Hamelin, Director of Development, by telephone at 403-210-6622 or on e-mail at c.hamelin@ucalgary.ca.

\section{EDITOR}

Barry Norris 